\title{
Mothers' Socialization of Emotions and Theory of Mind and Emotion Regulation in Children with Autism Spectrum Disorders
}

\author{
Nathalie Nader-Grosbois ${ }^{1}$, Emilie Jacobs ${ }^{1}$, Stéphanie Mazzone ${ }^{1}$, Nathalie Poirier ${ }^{2}$ \\ ${ }^{1}$ Chair Baron Frère in Special Education, Psychological Sciences Research Institute, UCLouvain, Louvain-la-Neuve, Belgium \\ ${ }^{2}$ Department of Psychology, Université du Québec à Montréal, Montréal, Québec, Canada \\ Email: nathalie.nader@uclouvain.be
}

How to cite this paper: Nader-Grosbois, N., Jacobs, E., Mazzone, S., \& Poirier, N. (2022). Mothers' Socialization of Emotions and Theory of Mind and Emotion Regulation in Children with Autism Spectrum Disorders. Psychology, 13, 177-219. https://doi.org/10.4236/psych.2022.131011

Received: November 9, 2021

Accepted: January 26, 2022

Published: January 29, 2022

Copyright $\odot 2022$ by author(s) and Scientific Research Publishing Inc. This work is licensed under the Creative Commons Attribution International License (CC BY 4.0).

http://creativecommons.org/licenses/by/4.0/

\begin{abstract}
This study compared Belgian and Quebec mothers' emotional profiles and socialization of the emotions of their children with autism spectrum disorders (ASD). It explored whether emotion-related reactions and conversations vary depending on children's or mothers' factors and culture. It examined the extent to which these maternal practices are linked with and predicted by children's Theory of Mind (ToM) or emotion regulation. The participants were 52 children from Quebec and 49 from Belgium, matched for age and severity of autism, and their mothers. In questionnaires, mothers reported on their own educational level, emotional openness, reactions to and conversations about emotions, and on their child's ASD symptoms, personality, ToM and emotion regulation. Independent $t$-tests showed that Belgian children had weaker emotion regulation than Quebec children, but similar levels in ToM; Belgian mothers were less emotionally open, they displayed less socialization of child's positive emotions, less problem-focused and encouragement of expression to child's negative emotions, and conversed less frequently about emotions with their child, than Quebec mothers. Other maternal reactions and the variety of emotional terms used were similar. In the whole sample, positive correlations were obtained between emotional verbs or terms used in conversations and children's ToM and emotion regulation. Hierarchical regressions showed that reactions to negative emotions, involving minimizing, comforting, focusing on the problem and encouraging expression, partly vary according to maternal emotional openness, educational level and culture; socialization of positive emotions partly varies according to culture and educational level. Three reactions to negative emotions were partially predicted by culture and child's age, the severity of ASD and ToM. Socialization of positive emotions was partially predicted by child's age, severity of ASD
\end{abstract}


and emotion regulation. Conversations about emotions varied depending on culture, child's age and severity of ASD. These conversations were linked positively with supportive reactions to negative and positive emotions.

\section{Keywords}

Mother-Child Conversations on Emotions, Mothers' Reactions to Emotions, Mothers' Emotional Competences, Theory of Mind, Emotion Regulation, Children with Autism Spectrum Disorders

\section{Introduction}

This article presents an exploratory cross-cultural study that examined how Belgian and Quebec mothers' emotional socialization practices with regard to their children with autism spectrum disorders (ASDs) vary depending on cultural, educational factors, the mothers' emotional profiles and the children's individual factors and socio-emotional abilities. To better understand ASD children's difficulties in adjusting their social behaviors in daily life, insight is needed into how they learn to understand their own mental states and those of others, and how they learn to regulate their emotions in social interactions (Nader-Grosbois, 2011a, 2011b; Yeates et al., 2007). Several risks and protection factors contribute to the development of Theory of Mind (ToM) (Astington, 1996; Flavell, 1999) and emotion regulation (Eisenberg \& Spinrad, 2004; Shields \& Cicchetti, 1997) in ASD children, as well as to parents' emotional profiles, their reactions to their children's emotions and parent-child conversations about emotions. To improve the support given to parents as socializers of emotions in their ASD children, it is important to investigate whether their culture, level of education, and emotional openness profiles affect the way they react to positive and negative emotions felt by their ASD children and the way they talk about emotions with them. Examining the extent to which these emotion-related socialization practices vary according to children's age, the severity of their autism symptoms, and their socio-emotional abilities may also help psychologists to improve parental guidance. The main theoretical background of this study exploring the interaction between socio-emotional abilities in ASD children and these maternal practices consisted of the heuristic model of social competences developed by Yeates et al. (2007) and adapted by Nader-Grosbois (2011b) and the model of Emotion-Related Socialization Behaviours (ERSBs) developed by Eisenberg et al. (1998), which integrate both cultural and individual factors in children and in their family.

Socio-emotional abilities: theory of mind and emotion regulation in TD and ASD children

The model of Yeates et al. (2007) adapted by Nader-Grosbois (2011b) postulates bidirectional links between three distinct complexity levels of social competences in typically and atypically developing children: 1) Social-cognitive 
processing, including ToM abilities; 2) Emotion regulation in social interactions in various contexts with peers and adults; 3) Social adjustment, reflecting the quality of social relationships. It considers the impact of both individual factors in children and family factors, including parental practices, on these three types of social competences and on their links. Studies have shown that typically developing (TD) children who have a good understanding of affective mental states (emotions, desires) and cognitive mental states (beliefs, thoughts, intentions, etc.), are likely to regulate their emotions better and to display prosocial and socially adjusted behaviors (Eisenberg, 2000; Eisenberg \& Spinrad, 2004; NaderGrosbois, 2011a; Simon \& Nader-Grosbois, 2021; Yeates et al., 2007).

About ASD children, studies emphasized deficits in ToM (Baron-Cohen et al., 1985), although there is inter-individual variability depending on factors such as age, developmental age, the severity of autism (Hutchins et al., 2016; Peterson et al., 2005; Steele et al., 2003) or executive functioning (Corbett et al., 2009), and depending on family or educational factors e.g. (Matthews et al., 2013). Deficits in emotion regulation, particularly for negative emotions, have also been reported in ASD children in numerous studies, including high levels of anxiety (Gomez \& Baird, 2005; Loveland, 2005; Nader-Grosbois \& Day, 2011; Samson et al., 2014, 2015; Southam-Gerow \& Kendall, 2002; Rieffe et al., 2011). ASD children show a lack of flexibility, mood lability, and dysregulated negative emotions, designated as "lability/negativity or emotion dysregulation" (Shields \& Cicchetti, 1997: p. 910). When they feel frustrated or face new situations, ASD children display emotion dysregulation, taking the form of emotional hyper- or hyposensitivity, inappropriate emotional responses or inadequate intensity of emotional expression or use ineffective regulation strategies (such as avoidance); however, there is inter-individual variability depending on ASD symptoms, personality factors, and cognitive factors (Cai et al., 2018; Gulsrud et al., 2010; Jahromi et al., 2012; Jahromi et al., 2013; Konstantareas \& Stewart, 2006; Maskey et al., 2013; Nader-Grosbois \& Mazzone, 2014; Rieffe et al., 2011; Samson et al., 2014, 2015). The regulation vs. dysregulation of emotions were differentiated in the questionnaire Emotion Regulation Checklist (ERC (Shields \& Cicchetti, 1997); French-version, ERC-vf (Nader-Grosbois \& Mazzone, 2015)), which assesses ASD children's profiles in a nuanced way, taking into account both their abilities and their difficulties with regulating their emotions in various situations of daily life. Moreover, studies have emphasized that ASD children's difficulties in inferring mental states by seeing things from another people's perspective and in regulating their emotions adversely affect their social adjustment and make them more likely to display behavior disorders through internalizing or externalizing problems (Jahromi et al., 2013; Mazefsky et al., 2014; Nader-Grosbois, 2011a, 2011b; Nader-Grosbois et al., 2012; Samson et al., 2014, 2015). Consequently, ToM and emotion regulation (in)abilities, beyond individual factors, in ASD children could contribute to explaining the variance of mothers' practices of socialization of emotions. The present study aims to explore this question. 


\section{Emotion-related socialization behaviors in parents}

The model of Eisenberg et al. (1998) looks at the effect of differences between parents in emotional expressiveness, reactions to their children's emotions, and emotion-related parent-child conversations on the development of ToM, emotion regulation and social adjustment in typically and atypically developing children. Parents' emotional competences, including the way they express and regulate their emotions, are observed by children and could serve as a model to be imitated (Eisenberg et al., 2003; Halberstadt et al., 1993). A distinction is made between "supportive" and "unsupportive" parental reactions to positive or negative emotions felt by children (Eisenberg et al., 1998, 1999; Eisenberg et al., 1996; Fabes et al., 2002; Mazzone \& Nader-Grosbois, 2015). "Supportive" reactions to a child's positive emotions include "encouragement" to express their emotions and "socialization", while "unsupportive" reactions are "reprimand" and "discomfort". When a child expresses negative emotions, "supportive" reactions are "encouragement" of emotional expression, "comforting", and "problemfocused responses", while "unsupportive" reactions are "distress", "punishment" or "minimizing" the child's emotions. Studies have investigated these reactions by parents using self-report questionnaires, the Coping with Children's Negative Emotions Scale (CCNES (Fabe et al., 2002)) or the Parental Reactions toward Positive and Negative Emotions questionnaire (QRPNE (Daffe \& NaderGrosbois, 2009)).

In addition, against the background of Vygotsky's socio-constructivist theory (Vygotsky, 1978), social interactions and exchanges by means of language within the family or in cultural groups, including parent-child conversations about emotions, social rules and conventions, and social experiences, have also been pointed to as favorable to socio-emotional abilities in children. During parentchild conversations, the parent may discuss causes and consequences of emotions (joy, anger, sadness, fear), use emotional vocabulary and explain emotional events experienced by the child or other people (Eisenberg et al., 1998; Mazzone \& Nader-Grosbois, 2015). Many studies have used an observation design to code these conversations, while some have used self-report questionnaires completed by parents, for example the Questionnaire of ParentChild Conversations about Emotions (QPCCE (Mazzone et al., 2017)).

Parents reactions to emotions and ToM or emotion regulation in TD and ASD children

Studies of TD children have emphasized that parents who react in a supportive way (notably with problem-focused responses, socialization, comforting and encouragement) foster their child's recognition of emotions in facial expressions, understanding of causes of emotions and ToM abilities related to affective or cognitive mental states (e.g. Burke et al., 2008; Denham et al., 1994; Denham et al., 2007; Eisenberg et al., 1996, Fabes et al., 2002; Jones et al., 2002; Mazzone \& Nader-Grosbois, 2016, 2017a; McElwain et al., 2007; Wong et al., 2008; Wong et al., 2009). Other studies have also highlighted that emotion regulation in TD 
children is positively predicted by supportive reactions on the part of parents (in particular comforting, encouragement and problem-solving in response to negative emotions), but negatively associated or predicted by unsupportive reactions (Eisenberg et al., 1999; Krause et al., 2003; Meyer et al., 2014; Mirabile et al., 2016; Morris et al., 2007; Perry et al., 2012; Shewark \& Blandon, 2015).

As ASD children show deficits in emotion expression, emotion regulation and ToM, some studies have explored the extent to which parental reactions to ASD children's emotions could be a protective or risk factor in these areas. A comparative study of maternal and paternal reactions to positive and negative emotions felt by their ASD child, using a questionnaire (QRPNE), showed that Belgian mothers displayed more encouragement and less minimizing responses to their ASD children's negative emotions than fathers (Mazzone \& Nader-Grosbois, 2017b). Specific links were obtained between each parent's reactions and ASD children's ToM abilities, which varied according to their understanding of "affective" or "cognitive" mental states, assessed by performance measures in two tests- "ToM-emotions" and "ToM-beliefs" (Nader-Grosbois \& Thirion-Marissiaux, 2011), and the Theory of Mind Inventory questionnaire (ToMI (Hutchins et al., 2012); ToMI-vf (Houssa et al., 2014)). These authors reported that a model including ASD children's developmental age, maternal comforting and problem-focused responses to negative emotions and maternal socialization to positive emotions explained $49 \%$ of the variance in ASD children's ToM-emotions score. Maternal comfort was negatively associated with ASD children's ToMemotions score. By contrast, maternal problem-focused and socialization responses were positively associated with ASD children's ToM-emotions score. Results showed that ASD children's developmental age explained $17 \%$ of the variance in the "ToMI-affective" (emotions and desires) score, and $23 \%$ of the variance in the "ToMI-thinking" (thinking and knowledge) score. The model including ASD children's age and maternal reprimand in response to positive emotions explained $21 \%$ of the variance in the children's ToM-beliefs score. Maternal reprimand was positively associated with children's ToM-beliefs score. The best predictors of ASD children's ToM-emotions and ToM-beliefs scores were individual children's characteristics and maternal reactions; however the best predictors of parents' perceptions as measured in ToMI-affective and ToMI-thinking were ASD children's characteristics, in particular their developmental age. No significant predictor was obtained for ToMI-beliefs. In their comparative study of mothers' reactions to emotions of ASD and TD children, Bougher-Muckian et al. (2016) revealed significant differences in maternal responses to anger and fear and suggested that mothers who encourage their ASD children to express their negative emotions during interactions offer them opportunities to learn to regulate their emotions. Mazzone (2018: p. 276) reported that comforting by fathers in response to negative emotions felt by ASD children by itself explained $15 \%$ of the variance in their emotion regulation. Thus, parents' scaffolding of emotions-the co-regulation by parents and their ASD children of the children's emotions-help the children to learn how to regulate 
emotions adequately in social interactions and reduce the risk of internalizing and externalizing problems (Gulsrud et al., 2010; Ting \& Weiss, 2017; Wilson et al., 2013). In the continuity of these findings in some previous research, the present study aims to explore to which extent both ToM and emotion regulation in ASD children could explain a part of variance of mothers' reactions to emotions, in considering also individual and cultural factors.

Parent-child conversations on emotions and ToM or emotion regulation in TD and ASD children

Numerous studies have described that parents use life events in the family or stories to discuss with their TD child on positive and negative emotions felt by a person or a character, about ways of expressing emotions, the causes and consequences of emotions, e.g. (Brumariu \& Kerns, 2015; Cui et al., 2020; Denham et al., 2007; Fivush et al., 2000; Garner, 2006; Garner et al., 2008; Garner \& Estep, 2001; Lagattuta \& Wellman, 2002; Lozada et al., 2016; Manczak et al., 2016; Mazzone et al., 2017; Ontai \& Thompson, 2002; Ruffman et al., 2002). In these conversations, parents ask questions about emotions, explain emotional events, propose to solve emotional problems, or use an "elaborative style". Frequent parent-child conversations about emotions and the use by parents of various terms to talk on emotions and mental states support the child's ToM development (Adrian et al., 2005; Denham et al., 1994; Jenkins et al., 2003; Laible, 2004, 2011; Laible \& Song, 2006; Labounty et al., 2008; Mazzone et al., 2017; Ontai \& Thompson, 2008; Reese et al., 2007; Ruffman et al., 2002) and her or his emotion regulation (Cui et al., 2020; Garner, 2006; Mazzone et al., 2017; Mazzone \& Nader-Grosbois, 2017a; Morelen \& Suveg, 2012). Aspects of parent-child conversations that are good predictors of TD children's socio-emotional abilities are the frequency of emotion-related conversations (Mazzone \& Nader-Grosbois, 2017a), the use of an elaborative style, e.g. (Laible, 2004; Ontai \& Thompson, 2008), giving explanations and asking open-ended questions about emotional situations, and the use of supportive strategies toward the child's feelings, e.g. (Morelen \& Suveg, 2012).

Concerning discussion about emotions and mental states, mothers of ASD children adjust the way they talk to the child's developmental level or abilities (Kay-Raining Bird et al., 2008; Mazzone \& Nader-Grosbois, 2017c; Slaughter et al., 2007). The study of Slaughter et al. (2007) showed that ASD children's ToM abilities (perspective-taking and false belief tasks) are positively linked with maternal clarification of affects (emotions and desires), but not with cognitive clarifications. In a comparative study, Mazzone \& Nader-Grosbois (2017c) reported that the frequency of emotion-related conversations between mothers and TD and ASD children and the number of emotional terms used by mothers did not differ and specified that ASD children's extraversion personality factor explained $25 \%$ of the variance in the number of emotional terms used by their mothers. The number of emotional terms used by mothers of ASD children explained $16 \%$ of the variance in ToMI-beliefs and $14 \%$ in that of ToMI-thinking (Mazzone, 2018: p. 277). In addition, Laurent \& Gor- 
man (2018) observed that parents' involvement in conversations about emotional states with their ASD child during a parent-child activity was positively related to the frequency of emotion regulation and social behaviors in the child. Costa et al. (2019) found that when parents of ASD children interact less with their child, he or she had more difficulties in recognizing, describing, and distinguishing emotions. Furthermore, parents' interactions with their child predicted emotional reactivity and emotion regulation problems in ASD children, except when the children's alexithymia was taken into account. In a recent study conducted by Beaudoin et al. (2021), a positive link was found between the frequency of emotion-related conversations by Quebec mothers with their ASD children and the children's emotion regulation abilities. Some individual factors in these children (age and personality) and mother-child conversations contributed to explaining the variance in emotion regulation. Recent studies on quality of emotional climate in families of ASD children, using "Five Minute Speech Samples" (FMSS) during parent-child conversations, have reported that some mothers of ASD children displayed criticism or difference in their warmth toward their ASD child, and this was associated with their child's emotional and behavioral problems (Baker et al., 2011; Griffith et al., 2015; Hickey et al., 2020; Smith et al., 2008). In addition, several programs for ASD children and their parents focusing on conversational practices about emotions and mental states through stories (especially comic strip conversations (Hutchins \& Prelock, 2008)) showed some effectiveness in improving these children's ToM or emotion regulation. Based on these preliminary findings, the question of links between ToM or emotion regulation in ASD children and the frequency of mother-child conversations, the number of emotional terms used by mothers to their children, will be examined in the present study, in considering individual and cultural factors.

\section{Links between emotion-related reactions and conversations}

In order to investigate coherence between ERSBs, the bidirectional links should be explored between parental supportive reactions to negative or positive emotions and the quality of parent-child conversations about emotions with TD and atypically developing children. In accordance with the model of Eisenberg et al. (1998), it seems relevant to study bidirectional links between parents' ERSBs and distinct socio-emotional competences in children, considering both parents' and child's mutual influences and agency in diverse aspects (Keller, 2007; Kuczynski et al., 1997; Trommsdorff \& Kornadt, 2003), and taking account of their individual and cultural factors. As no study reported any findings about these links, the present study will explore this question.

Individual and cultural factors in parents emotional competences and in their socialization of emotions

Different predictors of parents' reactions to or conversations about emotions have been examined. Some studies have emphasized that parents' gender, educational level or socio-economic level contribute to variation in these supportive or unsupportive reactions and conversations toward TD children, e.g. (Denham et 
al., 2007; Eisenberg et al., 1998; Fivush \& Wang, 2005; Garner et al., 1997; Garner et al., 1997; Mazzone \& Nader-Grosbois, 2017a), or children with intellectual disabilities (Jacobs et al., 2019a, 2019b; Nader-Grosbois et al., 2022) or autism spectrum disorders (Mazzone \& Nader-Grosbois, 2017c).

As parents of ASD children experience stressful parenting situations, have varying perceptions of the social support they receive and use different coping strategies with varying efficiency, their emotional competences, resilience and quality of life vary (Cappe et al., 2017, 2020; Nader-Grosbois \& Cappe, 2015). Such parents are also at greater risk of depressive symptoms (Baeza-Velasco et al., 2019). Given these risk factors, these parents may present fragility in their emotional profiles and live difficulties in their reactions to and conversations about their ASD child's emotions, as socializers of emotions. The more severe their children's autistic symptoms and behavior disorders, the harder it is for these parents to adjust their emotion-related socialization practices. Recent studies have examined whether specific dimensions of parents' emotional profiles help predict reactions to the emotions of their TD or intellectually disabled children (Nader-Grosbois et al., 2022), or toward ASD children (Mazzone \& Nader-Grosbois, 2017c) or their parent-child conversations about emotions. Several dimensions in mothers' emotional openness profiles have been found to be significant predictors of specific reactions to ASD children's emotions. For mothers of ASD children, Mazzone \& Nader-Grosbois (2017c) emphasized that their education level, emotional expressiveness and communication of their emotions explained $49 \%$ of the variance in their supportive reactions to their child's negative emotions. Mothers' regulation of emotions explained $25 \%$ of the variance in their unsupportive reactions to their child's negative emotions. Mothers' cognitive representation of emotions and the ASD child's conscientiousness explained $51 \%$ of the variance in maternal encouragement of the child's positive emotions. Mothers' regulation of emotions and cognitive representation of emotions and the ASD child's developmental age explained $40 \%$ of the variance in unsupportive maternal reactions to the child's positive emotions.

Moreover, as postulated in some models, notably those developed by Eisenberg et al. (1998), Dunsmore \& Halberstadt (1997, 2009), or Cole \& Tan (2007), it is also relevant to take account of the direct and indirect influence of cultural factors on parents' ERSBs. Cross-cultural studies conducted in European, Asian, American, African and Indian countries have highlighted cultural differences in parents' emotional expressiveness (Brown et al., 2015; Camras et al., 2008), or in their reactions to their TD children's emotions (Brown et al., 2015; Copapci et al., 2017; Garner, 2006; Grusec, 2002; Jaramillo et al., 2017) or their conversations about emotions with their TD children (Fivush \& Wang, 2005; Fivush et al., 2009; Grusec, 2002; Jaramillo et al., 2017). The results showed that parents' socialization practices and children's expression, regulation and understanding of emotions are embedded in a socio-cultural context 
and beliefs, and vary in different cultures, as explained by (Bornstein \& Bradley, 2003; Dunsmore \& Halberstadt, 1997, 2009; Grusec, 2002; Halberstadt et al., 2001; Keller, 2007; Trommsdorff \& Kornadt, 2003). Cultural aspects, beliefs, social rules and values orient the interpretation of emotional events and experiences and what is considered moral and desirable in the expression and regulation of positive and negative emotions and in social relationships (Hofstede, 2001; Mesquita \& Walker, 2003). These cultural variables induce different pathways of socialization of emotions in parents to help children to express and regulate their emotions according to social norms and cultural desirability (Cole et al., 2006; Friedlmeier et al., 2015; Kitayama et al., 2006). Consequently, these cultural factors should be considered in research on links between ERSBs in parents and socio-emotional abilities in atypically developing children. So far, very few cross-cultural studies have examined these parental practices with regard to atypically developing children, e.g. ((Nader-Grosbois et al., 2022) for children with intellectual disabilities). This study will take into account the culture by the comparison of Belgian and Quebec mothers' practices of socialization of emotions toward their ASD children.

\section{Objectives and Hypotheses of the Study}

This cross-cultural exploratory study compared Belgian and Quebec mothers' emotional profiles and their emotion-related socialization practices with their ASD children, and investigated how these maternal practices were linked to or predicted by individual and cultural factors in mothers and in ASD children, and by children's socio-emotional abilities. The interest of this study was based on the fact that, as cultures, Quebec and Belgium share the French language (including certain specific vocabulary and expressions), promote similar educational values oriented by autonomy and social inclusion for ASD children, and in the two countries, services are trying to improve the assistance given to parents to support their child's social adjustment. Despite these partial cross-cultural similarities, other aspects of each culture could cause differences in mothers' emotional profiles and ERSBs. For example, there are differences in the nature of the partnership between parents and professional support-providers, especially with regard to special needs in ASD children with heterogeneous ability profiles and in the implementation of evidence-based programs focused on socio-emotional abilities in child- and parent-targeted interventions (Abdeljalil \& Changkakoti, 2009; Nédélec-Trohel et al., 2015; Potvin et al., 2018). This comparative exploratory study aimed to identify similarities and differences between Belgian and Quebec mothers in their emotional profiles and in their reactions to and conversations about emotions with regard to their ASD children. Secondly, it examined predictors of these reactions and conversations, including mothers' factors (educational level, culture, emotional openness profiles), children's factors (age, personality, severity of autism) and children's ToM abilities and emotion regulation. The main hypotheses (broken down into operational sub-hypotheses in parentheses) were as follows: 
1) There are some cross-cultural differences in mothers' emotional profiles (H1a), in their specific supportive or unsupportive reactions to positive or negative emotions felt by their ASD child ( $\mathrm{H} 1 \mathrm{~b})$, and in mother-child conversations about emotions (H1c);

2) Specific supportive or unsupportive reactions by mothers to their ASD child's positive and negative emotions (H2a), and mother-child conversations about emotions (H2b) are linked to or vary depending on mothers' emotional openness profiles, culture (Belgium vs Quebec) and educational level;

3) ASD children's characteristics (age, personality factors, severity of autism), induce variability in mothers' specific reactions to positive and negative emotions ( $\mathrm{H} 3 \mathrm{a})$, and in mother-child conversations about emotions ( $\mathrm{H} 3 \mathrm{~b})$;

4) ASD children's theory of mind abilities and emotion regulation abilities induce variations in mothers' specific reactions to positive and negative emotions ( $\mathrm{H} 4 \mathrm{a})$, and mother-child conversations about emotions ( $\mathrm{H} 4 \mathrm{~b})$;

5) Positive links will be identified between mother-child conversations about emotions and maternal supportive reactions to emotions (H5), but not unsupportive reactions.

\section{Methods}

\subsection{Participants}

One hundred one children with ASD ( $90 \%$ boys) and their mothers were recruited in French-speaking areas of Belgium $(n=52)$ and in Quebec $(n=49)$. Among the inclusion criteria, children had to be diagnosed, by a psychologist at a center specializing in autism, as having ASD according to DSM-5 (Diagnostic and Statistical Manual of Mental Disorders) criteria, using the Autism Diagnostic Interview Revised (ADI-R), Autism Diagnostic Observation Schedule (ADOS) or PreLinguistic Autism Diagnostic Observation Schedule (PL-ADOS). In this study, participants were required to have mild to moderate autism (see the Measures section, CARS-T). Moreover, they had to be aged 4 to 13 years and to present a preschool learning level, corresponding to the cognitive and verbal communication abilities of typically developing children aged $3^{1 / 2}$ to 6 years. These inclusion criteria were chosen to enable measures of socio-emotional abilities in children to be applied and to match the two samples of children. The descriptive statistics are presented in Table 1 for children and in Table 2 for mothers. In Quebec, ASD children benefit from the school services and from the Centre de Réadaptation en Déficience Intellectuelle et Troubles Envahissants du Développement (CRDITED), which work in partnership with parents. In Belgium, ASD children receive adapted pedagogical support in special schools (type 3 ).

\subsection{Measures}

Childhood Autism Rating Scale (CARS-T (Schopler et al., 1980); French version (Rogé, 1989)) 
This questionnaire gives an estimation of the severity level of ASD. It assesses children's behavior in 15 domains: impairment in human relationships, imitation, inappropriate affect, bizarre use of body movement and persistence of stereotypes, peculiarities in relation to non-human objects, resistance to environmental change, peculiarities of visual responsiveness, peculiarities of auditory responsiveness, near receptor responsiveness, anxiety reaction, verbal communication (including all aspects of language, notably vocabulary and structure of sentences), non-verbal communication, activity level, intellectual functioning (including both competences and deficits), and general impressions of autism level. In each scale, 15 behavior items are scored on a continuum from 1 (normal behavior for children at the same age) to 4 (severely abnormal for a child at his or her age). Total scores can range from 15 to 60 . Scores below 30 indicate that the child is non-autistic, scores between 30 and 36.5 indicate that the child presents mild to moderate autism, and scores from 37 to 60 indicate severe autism (Schopler et al., 1980). The validation of this questionnaire revealed a very good internal consistency, with Cronbach's alpha of .94 and a good inter-rater reliability $(r=.71)$. The CARS-T was used to confirm the diagnosis of ASD in participants, in order to include only those who presented mild to moderate autism, intellectual functioning and verbal communication that would allow measures of theory of mind and emotion regulation to be applied, and make it possible to match two groups on their scores.

Bipolar Rating Scales based on the Five-Factor Model (EBMCF (Roskam et al., 2000))

This questionnaire measures adults' perception of children's personalities. It contains 25 items, five for each factor in the model (extraversion, agreeableness, conscientiousness, emotional stability and openness). The "extraversion" factor describes children who seek contact with others, are full of energy and often experience positive emotions. The "agreeableness" factor corresponds to children who are inclined to be empathic and cooperative due to their optimistic view of human nature. The "conscientiousness" factor characterizes children who are meticulous, careful and organized. The "emotional stability" factor corresponds to children who are stable, calm and less emotionally reactive. The "openness" factor describes children who are imaginative, curious and creative. The items take the form of pairs of adjectives (e.g., untidy-meticulous), one of which constitutes the positive pole and the other the negative pole. The mothers were asked to score children's characteristics on a 9-point scale. In the validation study, with 321 TD children, the factor analysis revealed the five expected factors, for which Cronbach's alpha was between .70 and .93. Coefficients of test-retest stability were highly significant and varied between .66 and .93 for teachers and between .80 and .89 for caregivers. This questionnaire was suitable for use with ASD children (Nader-Grosbois \& Mazzone, 2014).

Theory of Mind Inventory-French-version (ToMI-vf (Houssa et al., 2014); ToMI (Hutchins et al., 2012)) 
This questionnaire assesses parents' perceptions of their children's ToM competences. Parents rate their children's comprehension of affective and cognitive mental states (namely emotions, beliefs, false beliefs, desires, intentions, attention, perception, thinking, pretense play) through 39 items, on a scale ranging from 0 to 20. This measure is applicable to children aged from 2 to 12 years with or without a developmental disorder. A total score out of 20 can be obtained and three subscores can also be calculated, corresponding to the three factors identified. These factors are related to the child's comprehension of beliefs, socio-emotional mental states and thoughts. The validation of the French version matched that of the original version. Moreover, the French version showed significant internal consistency $(\alpha=.94)$ and test-retest reliability $(r=.86)$.

Emotion Regulation Checklist (ERC-vf (Nader-Grosbois \& Mazzone, 2015); $E R C$ (Shields \& Cicchetti, 1997))

This questionnaire assesses adults' perception of children's emotional regulation. It consists of 24 items assessing behaviors corresponding to emotional response and reactions of joy, anger, and empathy for peers and adults, as well as behaviors in situations of frustration or change of activity. This measure is applicable to children aged from 3 to 12 years with or without a developmental disorder. Parents evaluate the frequency of the behavior on a 4-point Likert scale ranging from "never" to "almost always". Two raw scores can be obtained: an emotional regulation score and an emotional dysregulation score. The sum of the two raw scores gives a composite emotional regulation score. The different raw scores can be averaged. The factor analysis for the French version of this questionnaire highlights two factors, namely "emotional regulation" and "emotional dysregulation”. Cronbach's alpha is .70.

\section{Mothers' Socio-educational level}

To estimate maternal socio-cultural level, mothers indicated on a questionnaire their level of education on a 9-point Likert scale $(1=$ elementary school not completed; 2 = elementary school; 3 = elementary special education school; $4=$ secondary school; 5 = secondary special education school; 6 = apprenticeship; 7 = bachelor's degree; $8=$ master's degree; $9=$ Ph.D.).

Dimensions of Openness to Emotions (DOE (Reicherts \& Genoud, 2012))

Based on the multidimensional model of affect processing, this 36-item questionnaire assesses parents' openness to emotional processes according to their subjective representations. Six subscales compose this measure. The CognitiveConceptual Representation of Emotions (REPCOG) subscale assesses individual knowledge about emotions and in particular the ability to differentiate affects, such as emotions, moods or emotional episodes (e.g. "I can accurately name every emotion or mood that I am feeling"). The Communication of Emotion (COMEMO) subscale evaluates individuals' ability to express (by facial expression, voice, gestures, etc.) their emotions or to intentionally verbalize the affective state they are experiencing in order to share and communicate with others (e.g. "For me, it is important to communicate to others how I am feel- 
ing"). The Perception of Internal and External Bodily Indicators of Emotions (PERINT and PEREXT) subscales assess the awareness that individuals have of their internal physiological states or of external indicators generated by their emotions and affective states (e.g. "In certain circumstances I recognize how I am feeling through my inner, physical reactions"). The Regulation of Emotion (REGEMO) subscale evaluates individuals' emotional regulation competences (e.g. "I manage to calm my feelings even in difficult situations"). The Normative Restrictions of Affectivity (RESNOR) subscale assesses individuals' perceptions of the social rules and conventions governing emotional expression and communication (e.g. "I would like feelings to be expressed more easily in our society"). Parents were asked to indicate on a 5-point scale ranging from 0 ("not at all") to 4 ("completely") to what extent each item corresponded to them. The factor analysis revealed the six factors corresponding to the respective theoretical dimensions, with Cronbach's alpha varying between .71 and .83 .

Parental Reactions toward Positive and Negative Emotions (Daffe \& Nader-Grosbois, 2009)

This questionnaire is an integrated version of two questionnaires, namely the Questionnaire sur les Réactions Parentales aux Émotions Positives Exprimées (QRPEPE, (Ladouceur et al., 2002)) and Coping with Children's Negative Emotion Scale (CCNES (Fabes et al., 2002); French version (Coutu et al., 2002)). It presents eight hypothetical scenarios in which a child feels negative (fear, sadness and anger) or positive (joy) emotions. For the scenarios related to negative emotions, six parental reactions are suggested: encouragement of emotional expression, comforting, problem-focused responses, distress, minimizing and punitive response; whereas for the positive emotions, four parental reactions are proposed: reprimand, discomfort, socialization and encouragement. Parents indicate to what extent they use different strategies on a 7-point Likert scale ranging from "very unlikely" to "very likely". The factor analysis of this questionnaire, validated on 328 parents of TD children, highlighted two subscales: supportive and unsupportive reactions for positive and negative emotions. Scores for supportive and unsupportive reactions and a score for each specific reaction can be calculated. Cronbach's alpha is .78 and .81 for negative scenarios and .77 and .62 for the joy scripts.

Questionnaire of Parent-Child Conversations about Emotions (QPCCE (Mazzone et al., 2017))

This questionnaire evaluates whether parent-child emotion-related conversations are more supportive or unsupportive, on a continuum. In the first part, parents have to classify according to their parenting priorities five domains: intellectual, adaptive, affective, motor and social. They are also asked to what extent they agree or disagree with four preliminary statements about emotions (e.g., "In general, I ask my child questions about his or her emotions (joy, sadness, fear, anger)"). The second part contains 24 items depicting supportive or unsupportive situation during parent-child emotion-related conversations. 
Parents indicate the frequency of the situation during the last two weeks on a 4 -point scale ranging from "not at all" to " 5 or more times". However, if parents have never experienced the described situation, a "not applicable" response is also possible. In the third part, a list of emotional terms (adjectives, nouns and verbs) related to joy, sadness, anger, fear is proposed, and parents are asked to indicate the terms they use in conversations with their child. The numbers of terms for each basic emotion and of each of three categories of words can be calculated, to indicate the variety of emotional terms used by parents during conversations with children. The factor analysis of this questionnaire (for the second part), validated on 300 parents, identifies a single factor. Items depicting unsupportive strategies are reversed. Cronbach's alpha is .91 .

\subsection{Procedure}

Before starting recruitment, the research procedure was approved by the Ethics Commission of the Psychological Sciences Research Institute of UCLouvain in Belgium and by the Research Ethics Board of the Université du Québec à Montréal, and the Joint Research Ethics Committee in Quebec. The recruitment was done on a voluntary basis, through a call for participation, via parents' associations (namely the Fédération québécoise de Pautisme, Autisme et Troubles Envahissants du Développement Montréal, the Association de Parents de PEnfance en Difficulté, and the Association de parents pour IÉpanouissement des Personnes Autistes in Québec; and the Association de Parents d'Enfants Autistes in Belgium) or special education schools (type 3) and specialized services for ASD children.

All parents were informed by a letter about the topic and modalities of the study. The parents' consent was obtained, by completing and signing a document. All questionnaires were filled out by mothers, in a paper or online version, according to their choice. The special teacher or a psychologist with professional practice working with the child completed the CARS-T. By completing the questionnaires, the mothers gave their perception of their child's personality, ToM abilities and emotional regulation. They also reported their own emotional openness, their reactions to their child's emotions and their conversations about emotions with their child.

\section{Results}

\subsection{Descriptive Statistics and Comparison between Cultural Groups of Children's Characteristics, ToM and Emotion Regulation Competences}

Table 1 presents descriptive statistics concerning Belgian and Quebec children's age, severity of ASD, gender distribution, competences in ToM and emotion regulation, and cross-cultural comparison, based on $t$-independent tests.

The children's age was approximately $7^{1 / 2}$ years on average, and ranged from 4 
Table 1. Descriptive analyses and independent $t$-tests between ASD children from Belgium and Quebec.

\begin{tabular}{|c|c|c|c|c|}
\hline & $\begin{array}{c}\text { Belgian } \\
\text { sample } \\
M(S D) \\
n=52\end{array}$ & $\begin{array}{c}\text { Quebec } \\
\text { sample } \\
M(S D) \\
n=49\end{array}$ & $X^{2} / t$ & $d$ \\
\hline \multicolumn{5}{|l|}{ Children's characteristics } \\
\hline Sex (\% boys) & $90 \%$ & $87 \%$ & .37 & \\
\hline Age in months & $90.42(24.96)$ & $\begin{array}{c}93.88 \\
(33.11)\end{array}$ & -.49 & \\
\hline Level of severity of ASD (CARS) & $32.04(5.95)$ & $31.63(6.26)$ & .27 & \\
\hline \multicolumn{5}{|l|}{ Children's personality factors (EBMCF) } \\
\hline Extraversion & $5.22(1.75)$ & $5.55(1.29)$ & -.87 & \\
\hline Emotional stability & $5.32(1.13)$ & $5.11(1.29)$ & .81 & \\
\hline Conscientiousness & $5.61(1.65)$ & $5.43(1.66)$ & .51 & \\
\hline Openness to experience & $5.54(1.7)$ & $6.44(1.41)$ & $-2.66^{*}$ & 1.54 \\
\hline Agreeableness & $5.59(1.52)$ & $6.21(1.39)$ & $-1.94 \dagger$ & 1.44 \\
\hline \multicolumn{5}{|l|}{ Children's socio-emotional competences } \\
\hline ToMI-Total $(\max =20)$ & $14.28(2.68)$ & $14.45(2.15)$ & -.20 & \\
\hline ToMI_“Thoughts” Factor 1 & $12.01(3.21)$ & $11.55(3.16)$ & .44 & \\
\hline ToMI-“Socio-emotional” Factor 2 & $15.87(2.22)$ & $17.28(1.99)$ & -1.99 & .67 \\
\hline ToMI_“Beliefs” Factor 3 & $16.76(3.04)$ & $17.10(1.91)$ & -.40 & \\
\hline Emotion Regulation & $2.53(.17)$ & $3.39(.35)$ & $-6.66^{* *}$ & 3.12 \\
\hline Emotion Dysregulation & $1.96(.11)$ & $1.77(.36)$ & .91 & \\
\hline
\end{tabular}

Notes: ASD = Autism spectrum disorder; $M=$ mean; $\mathrm{SD}=$ standard deviation; $\mathrm{EBMCF}=$ Bipolar Rating Scales based on the Five-Factor Model; ToMI $=$ ToM Inventory; $\dagger=.053$; ${ }^{\star} p<.01 ;{ }^{\star *} p=.001$.

to 13 years $(M=92.39 ; S D=29.13)$; the two samples did not differ on age. The CARS-T scores indicated that the Belgian and Quebec children presented mild to moderate autism, with no significant difference in the severity of ASD. The children were therefore well matched for these two variables. Concerning the personality factors in EBMCF, only one significant difference was obtained for openness: ASD children from Belgium were perceived as less imaginative, curious and creative than Quebec ASD children $(t=-2.66 ; p=.009 ; d=1.54)$. With regard to ToM abilities, the two samples did not differ significantly. The two samples of ASD children did not differ on emotion dysregulation but they differ on emotion regulation: Belgian ASD children regulated their emotions less easily than Quebec ASD children $(t=-5.75 ; p=.000 ; d=.44)$. 


\subsection{Descriptive Statistics and Comparison between Cultural Groups of Mothers' Characteristics, Emotion Profiles, Emotion-Related Reactions and Conversations}

Table 2 presents descriptive statistics about Belgian and Quebec mothers' age, educational level, emotional openness, reactions to their child's emotions and conversations about emotions, and cross-cultural comparison, based on $t$-independent tests.

Table 2. Descriptive analyses and independent $t$-tests between mothers from Belgium and Quebec.

\begin{tabular}{|c|c|c|c|c|}
\hline & $\begin{array}{c}\text { Belgian } \\
\text { sample } \\
M(S D) \\
n=52\end{array}$ & $\begin{array}{c}\text { Quebec } \\
\text { sample } \\
M(S D) \\
n=49\end{array}$ & $X^{2} / t$ & $d$ \\
\hline \multicolumn{5}{|l|}{ Mothers' characteristics } \\
\hline Age (in years) & $38.78(5.01)$ & $37.96(5.21)$ & 1.20 & \\
\hline Level of education ( $\%$ of superior grade) & $71 \%$ & $86 \%$ & 2.58 & \\
\hline \multicolumn{5}{|l|}{ Mothers emotional openness (DOE) } \\
\hline Cognitive representation of emotions & $2.75(.69)$ & $3.24(.62)$ & $-3.59^{\star * *}$ & .65 \\
\hline Communication of emotions & $2.31(.69)$ & $2.81(.46)$ & $-4.14^{\star \star \star}$ & .58 \\
\hline Perception of Internal Bodily Indicators of Emotions & $2.09(.99)$ & $3.27(.76)$ & $-6.23^{\star * *}$ & .88 \\
\hline Perception of External Bodily Indicators of Emotions & $2.04(.69)$ & $3.15(.61)$ & $-8.18^{\star \star \star}$ & .64 \\
\hline Regulation of emotions & $2.07(.62)$ & $2.98(.54)$ & $-7.47^{\star * *}$ & .58 \\
\hline Normative Restrictions of Affectivity & $1.99(1.03)$ & $3.13(1.12)$ & $-5.01^{\star * *}$ & 1.08 \\
\hline
\end{tabular}

\section{Mothers' reactions to negative emotions}

Comforting
Problem-focused
Encouragement of expression of emotion
Distress
Punitive
Minimizing responses

Mothers reactions to positive emotions

Socialization

Encouragement

Reprimand

Discomfort

\section{Mother-child conversations about emotions}

$\begin{array}{ccc}5.29(1.13) & 5.05(1.01) & 1.08 \\ 5.48(1.25) & 5.92(.78) & -2.04^{\star} \\ 4.39(1.42) & 5.14(.85) & -3.09^{\star \star} \\ 2.29(.85) & 2.28(.73) & -.09 \\ 2.1(.95) & 2.45(.96) & -1.73 \\ 3.69(1.08) & 3.53(1.15) & .65 \\ & & \\ & & \\ 5.11(1.39) & 5.84(1.01) & -2.87^{\star *} \\ 4.38(1.16) & 4.65(1.39) & -1.02 \\ 3.57(1.44) & 3.44(1.49) & -.43 \\ 2.73(1.63) & 2.81(1.44) & -.26\end{array}$

$\begin{array}{cccc}2.31(.78) & 2.73(.54) & -2.70^{\star *} & .64 \\ 4.81(2.79) & 5.55(3.13) & -1.10 & \\ 3.63(2.53) & 4.45(2.38) & -1.45 & \\ 1.87(1.52) & 2.51(1.65) & -1.76 & \\ 2.09(2.82) & 2.89(2.41) & -1.31 & \\ .87(1.22) & 1.98(1.73) & -2.76^{* *} & 1.58\end{array}$

Notes. ASD = Autism Spectrum Disorder; $M=$ mean; $\mathrm{SD}=$ standard deviation; ${ }^{*} p<.05 ;{ }^{* *} p<.01 ;{ }^{* * *} p=.001$. 
The mothers' ages ranged from 26 to 51 years $(M=38.31 ; S D=5.12)$ and the two samples did not differ on age. With regard to educational level, two subgroups were identified: 1) secondary school level and 2) higher educational level, including bachelor's, master's and PhD levels. No significant difference for educational levels was obtained between the two groups. The higher educational level had been reached by $71 \%$ of Belgian mothers and $86 \%$ of Quebec mothers.

Regarding maternal emotional profiles, significant differences appeared to the disadvantage of Belgian mothers, compared to Quebec mothers. Belgian mothers perceived themselves as less open to their own emotional processes: they were less able to identify their emotions $(t=-3.59)$, communicated their emotions less easily $(t=-4.14)$, were less aware of internal $(t=-6.23)$ and external $(t=$ -8.18 ) bodily indicators of emotions, regulated their emotions less easily $(t=$ $-7.47)$ and restricted their affectivity depending on social rules and conventions less easily $(t=-5.01)$ than Quebec mothers $(p=.001)$.

Concerning maternal reactions to children's emotions, some significant differences were obtained. In response to positive emotions felt by their child, Belgian mothers reported less supportive socialization reaction than Quebec mothers $(t=-2.87 ; p=.005)$. In response to their child's negative emotions, Belgian mothers reported less problem-focused reactions $(t=-2.04 ; p=.044)$ and less encouragement of emotional expression $(t=-3.09 ; p=.003)$ than Quebec mothers.

No difference was obtained for other supportive reactions and for unsupportive specific reactions to negative or positive emotions between the two groups. In addition, compared to Quebec mothers, Belgian mothers reported a lower frequency of conversations $(t=-2.70 ; p=.009)$ and the use of less varied emotion-related verbs with their child $(t=-2.76 ; p<.01)$, but no difference appeared between the groups for the variety of terms about each emotion.

\subsection{Mothers' Emotion-Related Behaviors and Maternal Factors}

As preliminary analyses, Spearman coefficients of correlation were calculated between mothers' subscores for emotional openness and their scores for specific reactions to their child's emotions and the frequency of conversations about emotions (see Table 3).

Maternal cognitive-conceptual representation of emotions was linked positively and significantly with problem-focused reaction $(r=.286 ; p=.006)$ and encouragement of expression of emotions $(r=.339 ; p=.001)$, but negatively with minimizing responses $(r=-.255 ; p=.015)$. Maternal perception of internal bodily indicators of emotions was positively and significantly linked with encouragement of expression of negative emotions $(r=.277 ; p=.008)$ and with mother-child conversations about emotions $(r=.230 ; p=.043)$, and the use of a variety of sadness terms $(r=.324 ; p=.004)$. While maternal perception of external bodily indicators of emotions was positively and significantly linked to 
Table 3. Spearman correlations between mothers' emotions-related reactions and conversations, and maternal emotional openness.

\begin{tabular}{|c|c|c|c|c|c|c|}
\hline & \multicolumn{6}{|c|}{ Mothers' emotional openness (DOE) } \\
\hline & REPCOG & COMEMO & PERINT & PEREXT & REGEMO & RESNOR \\
\hline \multicolumn{7}{|l|}{ Mothers reactions to negative emotions } \\
\hline Comforting & .151 & .159 & -.036 & .049 & -.111 & .082 \\
\hline Problem-focused & $.286^{\star *}$ & .083 & .119 & .059 & .107 & .190 \\
\hline Encouragement of expression of emotion & $.339^{* * * *}$ & .117 & $.277^{\star *}$ & .204 & .139 & $.280^{\star *}$ \\
\hline Distress & -.151 & .032 & .026 & .110 & -.207 & .038 \\
\hline Punitive & -.037 & .184 & .004 & $.217^{\star}$ & -.040 & .139 \\
\hline Minimizing responses & $-.255^{\star}$ & .180 & -.119 & .068 & -.034 & .059 \\
\hline \multicolumn{7}{|l|}{ Mothers reactions to positive emotions } \\
\hline Socialization & .103 & .099 & .056 & .169 & .131 & $.311^{\star *}$ \\
\hline Encouragement & .139 & .055 & .034 & $.211^{\star}$ & -.054 & .089 \\
\hline Reprimand & -.11 & .057 & .043 & .074 & -.148 & .027 \\
\hline Discomfort & .059 & .154 & .177 & .139 & -.052 & .143 \\
\hline Mother-child conversations about emotions & .173 & .032 & $.230^{*}$ & .151 & .197 & $.252^{*}$ \\
\hline Joy-related terms & .063 & -.179 & .113 & .030 & -.016 & .048 \\
\hline Anger-related terms & .053 & -.022 & .196 & .166 & -.054 & .106 \\
\hline Sadness-related terms & .061 & .173 & $.324^{\star * *}$ & $.235^{\star}$ & .041 & .212 \\
\hline Fear-related terms & .098 & .064 & .220 & .209 & -.026 & .090 \\
\hline Emotion-related verbs & .189 & -.137 & .225 & .114 & .106 & .201 \\
\hline
\end{tabular}

Notes REPCOG = Cognitive-Conceptual Representation of Emotions; COMEMO = Communication of Emotion; PERINT = Perception of Internal Bodily Indicators of Emotions; PEREXT = Perception of External Bodily Indicators of Emotions; REGEMO $=$ Regulation of Emotion; RESNOR = Normative Restrictions of Affectivity; ${ }^{*} p<.05 ;{ }^{* *} p<.01 ;{ }^{* *} p<.005 ;{ }^{* * * *} p<.001$.

punitive responses to the child's negative emotions $(r=.217 ; p=.040)$, to encouragement of positive emotions $(r=.211 ; p=.047)$, and to the use of a variety of sadness terms in conversations $(r=.235 ; p=.038)$. Maternal normative restrictions of affectivity were positively and significantly linked to encouragement of expression of negative emotions $(r=.280 ; p=.008)$, to socialization of positive emotions $(r=.311 ; p=.003)$ and to mother-child conversations about emotions $(r=.252 ; p=.027)$.

In order to explore the extent to which mothers' factors (culture, educational level and emotional openness) predict the variance in their reactions to their child's emotions and in mother-child conversations about emotions, hierarchical regression analyses with an enter method were used. In Step 1, the country and mothers' educational levels were entered. In Step 2, four subscores related to mother's emotional openness were entered: cognitive-conceptual representation of emotions, communication of emotions, emotion regulation, and normative restrictions of affectivity. 
Table 4 presents the significant results of these hierarchical regression analyses, indicating significant predictors of maternal reactions and conversations. Regarding maternal reaction toward the child's negative emotions, $10 \%$ of the variance in minimizing responses was explained by a Model 2 in which maternal

Table 4. Predictors of mothers' reactions and conversations about emotions depending on maternal factors.

\begin{tabular}{|c|c|c|c|c|c|c|c|c|}
\hline \multirow{3}{*}{ Predictors } & \multicolumn{8}{|c|}{ Mothers reactions to negative emotions } \\
\hline & \multicolumn{2}{|c|}{ Minimizing } & \multicolumn{2}{|c|}{ Comforting } & \multicolumn{2}{|c|}{ Problem-focused reaction } & \multicolumn{2}{|c|}{ Encouragement } \\
\hline & $\beta$ & $R^{2}$ adj & $\beta$ & $R^{2}$ adj & $\beta$ & $R^{2}$ adj & $\beta$ & $R^{2}$ adj \\
\hline Model 1 & & -.01 & & .03 & & $.05^{*}$ & & $.10^{* *}$ \\
\hline Culture & -.086 & & -.214 & & .134 & & .181 & \\
\hline Educational level & -.045 & & .133 & & $.230^{*}$ & & $.276^{*}$ & \\
\hline Model 2 & & $.10^{*}$ & & $.14^{*}$ & & $.21^{* * *}$ & & $.21^{* * *}$ \\
\hline Culture & -.095 & & $-.537^{* * *}$ & & -.166 & & .001 & \\
\hline Educational level & -.063 & & .062 & & .154 & & $.242^{*}$ & \\
\hline DOE-REPCOG & $-.270^{*}$ & & $.254^{*}$ & & $.374^{* * *}$ & & $.352^{* * *}$ & \\
\hline DOE-COMEMO & $.384^{* *}$ & & .202 & & .128 & & .003 & \\
\hline DOE-REGEMO & -.056 & & .185 & & .178 & & -.003 & \\
\hline DOE-RESNOR & -.036 & & .133 & & .075 & & .189 & \\
\hline \multirow{3}{*}{ Predictors } & \multicolumn{3}{|c|}{ Mothers reactions to positive emotions } & & & & & \\
\hline & \multicolumn{3}{|c|}{ Socialization } & & & & & \\
\hline & $\beta$ & & $R^{2}$ adj & & & & & \\
\hline Model 1 & & & $.05^{*}$ & & & & & \\
\hline Culture & $.216^{*}$ & & & & & & & \\
\hline Educational level & .147 & & & & & & & \\
\hline Model 2 & & & .05 & & & & & \\
\hline Culture & .134 & & & & & & & \\
\hline Educational level & .149 & & & & & & & \\
\hline DOE-REPCOG & .097 & & & & & & & \\
\hline DOE-COMEMO & -.048 & & & & & & & \\
\hline DOE-REGEMO & -.027 & & & & & & & \\
\hline DOE-RESNOR & .205 & & & & & & & \\
\hline \multirow{2}{*}{ Predictors } & \multicolumn{3}{|c|}{ Conversations about emotions } & & & & & \\
\hline & $\beta$ & & $R^{2}$ adj & & & & & \\
\hline \multicolumn{9}{|l|}{ Model 1} \\
\hline Culture & .204 & & & & & & & \\
\hline Educational level & .191 & & & & & & & \\
\hline Model 2 & & & $.07^{*}$ & & & & & \\
\hline Culture & .101 & & & & & & & \\
\hline Educational level & .173 & & & & & & & \\
\hline DOE-REPCOG & .141 & & .05 & & & & & \\
\hline DOE-COMEMO & -.137 & & & & & & & \\
\hline DOE-REGEMO & .105 & & & & & & & \\
\hline DOE-RESNOR & .093 & & & & & & & \\
\hline
\end{tabular}

Notes REPCOG = Cognitive-Conceptual Representation of Emotions; COMEMO = Communication of Emotion; REGEMO = Regulation of Emotion; RESNOR $=$ Normative Restrictions of Affectivity; ${ }^{*} p<.05,{ }^{* *} p<.01,{ }^{* *} p=.001$. 
cognitive-conceptual representations of emotions $(\beta=-.270 ; p=.020)$ and communication of emotions $(\beta=.384 ; p=.002)$ were significant predictors. $14 \%$ of the variance in comforting $(\beta=.401 ; p<.05)$ was explained by a Model 2 in which culture $(\beta=-.537 ; p=.001)$ and maternal cognitive-conceptual representations of emotions $(\beta=.254 ; p=.024)$ were significant predictors. $21 \%$ of the variance in problem-focused reaction was explained by a Model 2 including maternal cognitive-conceptual representations of emotions as a significant predictor $(\beta=.374 ; p=.001) .21 \%$ of the variance in encouragement of emotional expression was explained by a Model 2 including the following significant predictors: maternal educational level $(\beta=.242 ; p=.022)$ and cognitive-conceptual representations of emotions $(\beta=.352 ; p=.001)$. The variance of no other reaction to negative emotions felt by the child was significantly explained by Model 1 or 2, although maternal emotion regulation was a significant predictor in Model $2(\beta=-.346 ; p=.025)$. Concerning maternal reaction to child's positive emotions, $5 \%$ of the variance in socialization was explained by a Model 1 including culture and maternal educational level. In addition, $7 \%$ of the variance in mother-child conversations about emotions was explained by a Model 1 including culture and maternal educational level.

\subsection{Mothers' Emotion-Related Behaviors and ASD Children's Factors}

Table 5 presents correlations between mothers' reactions, conversations about emotions and children's characteristics. Only one significant positive correlation

Table 5. Spearman correlations between mothers' reactions and conversations about emotions and children's characteristics.

\begin{tabular}{|c|c|c|c|c|c|c|c|c|}
\hline & $\begin{array}{l}\text { Children's } \\
\text { age }\end{array}$ & CARS-T & EBMCF_E & EBMCF_S & EBMCF_C & EBMCF_O & EBMCF_A & $\begin{array}{l}\text { Children's } \\
\text { age }\end{array}$ \\
\hline \multicolumn{9}{|c|}{ Mothers' reactions to negative emotions } \\
\hline Comforting & -.168 & .138 & -.159 & .169 & .201 & .082 & -.007 & -.168 \\
\hline Problem-focused & .048 & -.075 & -.052 & -.144 & -.022 & -.040 & .097 & .048 \\
\hline $\begin{array}{c}\text { Encouragement of expression } \\
\text { of emotion }\end{array}$ & -.012 & .030 & -.007 & .088 & -.134 & -.049 & -.003 & -.012 \\
\hline Distress & .132 & .074 & .118 & -.045 & .217 & .198 & .195 & .132 \\
\hline Punitive & .151 & .112 & .158 & .044 & .166 & .137 & .046 & .151 \\
\hline Minimizing responses & .101 & .103 & -.054 & -.083 & .168 & .021 & .073 & .101 \\
\hline \multicolumn{9}{|c|}{ Mothers reactions to positive emotions } \\
\hline Socialization & -.058 & .070 & -.005 & .019 & -.095 & .217 & .205 & -.058 \\
\hline Encouragement & -.148 & -.001 & -.008 & .194 & $.254^{\star}$ & -.002 & .164 & -.148 \\
\hline Reprimand & .138 & .108 & -.130 & -.018 & .105 & .065 & .031 & .138 \\
\hline Discomfort & .140 & -.115 & -.072 & -.112 & -.072 & .069 & .002 & .140 \\
\hline $\begin{array}{l}\text { Mother-child conversations } \\
\text { about emotions }\end{array}$ & -.125 & -.030 & .113 & -.212 & -.165 & .057 & .146 & -.125 \\
\hline
\end{tabular}

Notes. EBMCF = Bipolar Rating Scales based on the Five-Factor Model; E = Extraversion; $\mathrm{S}=$ Emotional Stability; C = Conscientiousness; $\mathrm{O}=$ Openness; $\mathrm{A}=$ Agreeableness; ${ }^{\star} p<.05$. 
was obtained between maternal encouragement of positive emotions and the child's conscientiousness $(r=.254 ; p=.024)$. In order to explore the extent to which culture and children's characteristics (age, severity of ASD and personality factors) predicted part of the variance in mothers' reactions and conversations, hierarchical regression analyses with an enter method were used. The country, child's age and severity of ASD were entered in Step 1. The five personality factors (extraversion, emotional stability, conscientiousness, openness and agreeableness) were entered in Step 2. Table 6 presents the results concerning significant predictors of mothers' ERSBs. Maternal reaction of distress to child's negative

Table 6. Predictors of mothers' reactions and conversations depending on culture and children's characteristics.

\begin{tabular}{|c|c|c|c|c|}
\hline \multirow{3}{*}{ Predictors } & \multicolumn{4}{|c|}{ Mothers reactions to negative emotions } \\
\hline & \multicolumn{2}{|c|}{ Distress } & \multicolumn{2}{|c|}{ Encouragement } \\
\hline & $\beta$ & $R^{2}$ adj & $\beta$ & $R^{2}$ adj \\
\hline Model 1 & & -.01 & & $.08^{*}$ \\
\hline Culture & -.112 & & $.343^{\star *}$ & \\
\hline Children's Age & .136 & & -.017 & \\
\hline ASD Severity & .069 & & .143 & \\
\hline Model 2 & & $.12^{*}$ & & .06 \\
\hline Culture & -.172 & & .308 & \\
\hline Children's Age & .172 & & .002 & \\
\hline ASD Severity & .167 & & .137 & \\
\hline Extraversion & -.018 & & -.047 & \\
\hline Emotional Stability & -.257 & & .222 & \\
\hline Conscientiousness & $.293 \dagger$ & & -.205 & \\
\hline Openness & .183 & & .153 & \\
\hline Agreeableness & .172 & & -.022 & \\
\hline \multirow{2}{*}{ Predictors } & \multicolumn{3}{|c|}{ Conversations about emotions } & \\
\hline & $\beta$ & & & \\
\hline Model 1 & & & & \\
\hline Culture & $.393^{\star *}$ & & & \\
\hline Children's Age & -.113 & & & \\
\hline ASD Severity & .074 & & & \\
\hline Model 2 & & & & \\
\hline Culture & $.348^{\star}$ & & & \\
\hline Children's Age & -.097 & & & \\
\hline ASD Severity & .090 & & & \\
\hline Extraversion & .034 & & & \\
\hline Emotional Stability & -.239 & & & \\
\hline Conscientiousness & -.059 & & & \\
\hline Openness & .007 & & & \\
\hline Agreeableness & .064 & & & \\
\hline
\end{tabular}


emotions was the only reaction predicted by a Model 2 (including culture, age, severity of ASD and personality): $12 \%$ of the variance in distress was explained by this model, in which the conscientiousness factor in the child's personality was nearly statistically significant as a predictor $(\beta=.293 ; p=.056)$. Model 1 (including culture, age, severity of ASD) in which culture was a significant predictor, explained $8 \%$ of the variance in maternal encouragement of child's negative emotions $(\beta=.343 ; p=.007)$ and $12 \%$ of the variance in mother-child conversations about emotions $(\beta=.393 ; p=.003)$.

\subsection{Mothers' Emotion-Related Behaviors and ASD Children's ToM and Emotion Regulation}

The correlations between mothers' reactions and children's ToM competences and emotion regulation in Table 7 showed that children's ToM competences were linked to three maternal reactions: negatively with comforting $(r=-.240 ; p$ $=.030)$, and positively with distress $(r=.244 ; p=.027)$ and discomfort $(r=.222$; $p=.045)$. Another positive significant correlation was obtained between punitive maternal responses to child's negative emotions and child's emotion regulation $(r=.252 ; p<.02)$.

Table 8 presents correlations between mother-child conversations and children's ToM competences and emotion regulation. Positive significant correlations were obtained between emotions-related verbs, terms describing positive and negative emotions (joy, anger, sadness, fear) used in mother-child conversations and children's ToM abilities (total, thoughts, beliefs, socio-emotional scores),

Table 7. Spearman correlations between mothers' reactions to emotions and children's ToM.

$\begin{array}{cccccc}\text { ToMI } & \text { ToMI } & \text { ToMI } & \text { ToMI } & \text { Emotion } & \text { Emotion } \\ & \text { Thoughts } & \text { Socio-emotional } & \text { Belief } & \text { regulation } & \text { dysregulation }\end{array}$

\section{Mothers' reactions to negative emotions}

\begin{tabular}{|c|c|c|c|c|c|c|}
\hline Comforting & $-.240^{\star}$ & $-.309^{* *}$ & -.084 & -.200 & -.123 & -.104 \\
\hline Problem-focused & .110 & .046 & .047 & .129 & .095 & .005 \\
\hline Encouragement of expression of emotion & .108 & .057 & .040 & .064 & .066 & .000 \\
\hline Distress & $.244^{*}$ & $.239^{*}$ & $.248^{\star}$ & $.286^{* *}$ & .033 & .006 \\
\hline Punitive & .072 & .039 & .106 & .114 & $.252^{\star}$ & .103 \\
\hline Minimizing responses & -.043 & -.102 & .048 & -.001 & -.014 & -.047 \\
\hline \multicolumn{7}{|l|}{ Mothers' reactions to positive emotions } \\
\hline Socialization & .013 & -.033 & .101 & .031 & .118 & -.205 \\
\hline Encouragement & -.134 & -.152 & -.150 & -.134 & .121 & -.080 \\
\hline Reprimand & -.004 & -.028 & .046 & .055 & .008 & .105 \\
\hline Discomfort & $.222^{\star}$ & $.230^{\star}$ & .181 & .207 & .119 & .140 \\
\hline
\end{tabular}

Notes. ToMI $=$ ToM Inventory; ${ }^{*} p<.05 ;{ }^{*} p<.01$. 
Table 8. Spearman correlations between mother-child conversations about emotions and children's ToM and emotion regulation.

\begin{tabular}{|c|c|c|c|c|c|c|}
\hline & ToMI & $\begin{array}{l}\text { ToMI } \\
\text { Thoughts }\end{array}$ & $\begin{array}{c}\text { ToMI } \\
\text { Socio-emotional }\end{array}$ & $\begin{array}{l}\text { ToMI } \\
\text { Belief }\end{array}$ & $\begin{array}{l}\text { Emotion } \\
\text { regulation }\end{array}$ & $\begin{array}{c}\text { Emotion } \\
\text { dysregulation }\end{array}$ \\
\hline Emotion-related conversations & -.045 & -.066 & .050 & -.041 & .226 & -.038 \\
\hline Joy-related terms & $.433^{* * * *}$ & $.327^{\star * *}$ & $.258^{\star}$ & $.359^{* * *}$ & $.338^{\star * *}$ & -.205 \\
\hline Anger-related terms & $.365^{\star * *}$ & $.335^{\star * *}$ & $.292^{\star *}$ & $.376^{* * *}$ & .217 & .030 \\
\hline Sadness-related terms & $.244^{*}$ & $.243^{*}$ & $.285^{\star}$ & $.239^{*}$ & $.340^{* * *}$ & -.006 \\
\hline Fear-related terms & $.354^{\star * \star}$ & $.408^{* * * *}$ & $.340^{* * *}$ & $.351^{\star * \star}$ & .199 & -.031 \\
\hline Emotion-related verbs & $.386^{\star * *}$ & $.337^{\star *}$ & $.314^{\star *}$ & $.319^{* *}$ & $.284^{*}$ & -.195 \\
\hline
\end{tabular}

Notes: ${ }^{\star} p<.05,{ }^{* *} p<.01 ;{ }^{* * *} p<.005 ;{ }^{* * *} p<.001$.

and also between emotion-related verbs, terms describing joy or anger in conversations and children's emotion regulation.

To explore the extent to which, irrespective of children's age, the severity of their ASD and their personality, part of the variance in mothers' specific reactions and conversations about emotions was explained by their children's ToM competences or emotion regulation versus dysregulation, hierarchical regression analyses with an enter method were used. In Step 1, children's age and the severity of their ASD were entered, and in Step 2 their scores for ToM or emotion regulation and dysregulation were entered. Table 9 and Table 10 present the results of the hierarchical regression analyses, presenting significant predictors of maternal reactions and conversations among children's factors, and children's ToM competences or emotion regulation and dysregulation respectively. Only two maternal reactions to negative emotions were predicted by a Model 2, and these reactions were not the same depending on whether the total ToMI score or the three subscores (thoughts, socio-emotional, beliefs) were considered in Step 2. More particularly, $9 \%$ of the variance in distress was explained by a Model 2 including child's age, severity of ASD and total ToMI score, in which child's ToM competences (ToMI Total; $\beta=.446 ; p=.005$ ) was the only significant predictor. Similarly, $13 \%$ of the variance in comforting reaction was predicted by this Model 2 in which child's ToM competences (ToMI Total; $\beta=-.334 ; p$ $=.029$ ) was also the only significant predictor. Looking at the results of regressions considering the three subscores of ToMI, the variance in comforting reaction was explained by the ToMI "Thought" score $(\beta=-.591 ; p=.014) .13 \%$ of the variance in problem-focused reaction was predicted by a Model 2 in which the ToMI "Socio-emotional" score $(\beta=-.557 ; p=.008)$ and ToMI "Belief" score ( $\beta=.704 ; p=.015)$ were significant predictors.

In regressions considering child's emotion regulation in Step 2, only 9\% of the variance in socialization of positive emotions was predicted by a Model 2 in which emotion regulation $(\beta=-.353 ; p=.006)$ was the only significant predictor (see Table 10). No significant result was obtained in these regression analyses to predict the frequency of mother-child conversations about emotions. 
Table 9. Predictors of mothers' reactions to emotions depending on children's characteristics and ToM competences.

\begin{tabular}{|c|c|c|c|c|}
\hline \multirow{3}{*}{ Predictors } & \multicolumn{4}{|c|}{ Mothers reactions to negative emotions } \\
\hline & \multicolumn{2}{|c|}{ Distress } & \multicolumn{2}{|c|}{ Comforting } \\
\hline & $\beta$ & $R^{2} a d j$ & $\beta$ & $R^{2}$ adj \\
\hline Model 1 & & -.02 & & $.07^{\star}$ \\
\hline Children's Age & .068 & & -.202 & \\
\hline ASD Severity & .087 & & .227 & \\
\hline Model 2 & & $.09^{*}$ & & $.13^{*}$ \\
\hline Children's Age & .213 & & .133 & \\
\hline ASD Severity & -.143 & & -.044 & \\
\hline ToMI-Total & $.446^{\star *}$ & & $-.334^{*}$ & \\
\hline \multirow{3}{*}{ Predictors } & \multicolumn{4}{|c|}{ Mothers' reactions to negative emotions } \\
\hline & \multicolumn{2}{|c|}{ Distress } & \multicolumn{2}{|c|}{ Comforting } \\
\hline & $\beta$ & $R^{2} a d j$ & $\beta$ & $R^{2}$ adj \\
\hline Model 1 & & .02 & & -.01 \\
\hline Children's Age & -.078 & & $.130^{*}$ & \\
\hline ASD Severity & .217 & & .059 & \\
\hline Model 2 & & $.13^{*}$ & & $.13^{*}$ \\
\hline Children's Age & .141 & & .228 & \\
\hline ASD Severity & .130 & & .032 & \\
\hline ToMI-Thoughts & $-.591^{\star}$ & & -.424 & \\
\hline ToMI-Socioemotional & .025 & & $-.557^{\star \star}$ & \\
\hline ToMI-Beliefs & .151 & & $.704^{\star}$ & \\
\hline
\end{tabular}

Notes: ToMI $=$ ToM Inventory; ${ }^{\star} p<.05,{ }^{*} p<.01$.

Table 10. Predictors of mothers' reactions depending on children's characteristics, emotion regulation and dysregulation.

\begin{tabular}{ccc}
\hline & \multicolumn{2}{c}{ Mothers reactions to negative emotions } \\
\cline { 2 - 3 } Predictors & \multicolumn{2}{c}{ Distress } \\
\cline { 2 - 3 } & & $\boldsymbol{R}^{2}$ adj \\
Model 1 & -.144 & -.01 \\
Children's Age & .036 & $.09^{*}$ \\
ASD Severity & & \\
Model 2 & -.172 & \\
Children's Age & .124 & \\
ASD Severity & $-.353^{* *}$ & \\
Emotion regulation & .102 & \\
Emotion dysregulation & & \\
\hline
\end{tabular}

Notes: ${ }^{\star} p<.05,{ }^{\star *} p<.01$. 


\subsection{Links between Maternal Reactions to ASD Child's Emotions and Mother-Child Conversations about Emotions}

In order to explore links for the whole sample between maternal reactions to child's positive and negative emotions and frequency of mother-child conversations about emotions, Spearman coefficients of correlation were calculated (see Table 11). Results showed that mother-child conversations about emotions were positively related to the three supportive reactions to child's negative emotions, namely comforting $(r=.233 ; p=.039)$, problem-focused reaction $(r=.352 ; p$ $=.001)$ and encouragement of expression of emotions $(r=.451 ; p=.000)$. Regarding maternal reaction to child's positive emotion, only socialization, a supportive reaction, was significantly correlated to mother-child conversations about emotions $(r=.325 ; p=.004)$.

Table 11. Spearman correlations between mothers' reactions and conversations.

\begin{tabular}{lc}
\hline & $\begin{array}{c}\text { Mothers-child conversations } \\
\text { about emotions }\end{array}$ \\
\hline Mothers' reactions to negative emotions & $.233^{*}$ \\
Comforting & $.352^{* * *}$ \\
Problem-focused & $.451^{* * *}$ \\
Encouragement of expression of emotion & -.029 \\
Distress & .035 \\
Punitive & .060 \\
Minimizing responses & \\
Mothers' reactions to positive emotions & $.325^{* *}$ \\
Socialization & .114 \\
Encouragement & .128 \\
Reprimand & -.007 \\
Discomfort & \\
\hline
\end{tabular}

Note: ${ }^{\star} p<.05 ;{ }^{* *} p<.01 ;{ }^{* * *} p=.001$.

\section{Discussion}

The aims of this study were, first, to compare the emotional profiles and practices of emotion socialization with regard to their ASD children of mothers in Quebec and Belgium and, second, to investigate how reactions and conversations were linked with or predicted by factors specific to mothers and children respectively, including culture.

\section{Mothers emotional profiles}

First, concerning the perceptions of mothers from both countries about their emotional profiles, hypothesis H1a of cultural differences was confirmed for all dimensions of their emotional openness. In comparison to Quebec mothers, Belgian mothers perceived themselves as identifying, communicating and regu- 
lating their emotions less, as being less aware of internal and external bodily indicators of emotions, and as restricting their affectivity less to take account of social rules or conventions. This cross-cultural variability in perceptions of emotional openness by mothers from these two cultures could be explained as indicating that the interpretation of emotional events, socially prescribed ways of expressing and regulating positive or negative feelings, social norms and desirability in emotional and relational domains vary depending on the culture (Cole, et al., 2006; Copapci et al., 2017; Friedlmeier et al., 2015; Hofstede, 2001; Kitayama et al., 2006; Mesquita \& Walker, 2003).

\section{Mothers' reactions to their ASD child s emotions}

Second, concerning maternal reactions, cultural differences were observed only very partially, specifically for socialization of positive emotions, problem-focused reactions and encouragement of emotional expression in response to negative emotions, in the sense that Belgian mothers displayed these reactions less than Quebec mothers. Several similarities between the two cultural groups appeared in comforting, distress, punitive and minimizing reactions to negative emotions expressed by the ASD child and also in encouragement, reprimand and discomfort in response to the child's positive emotions. Hypothesis H1b, that there would be some similarities and some differences between these two cultural groups of mothers in terms of specific supportive or unsupportive reactions, was thus confirmed. These findings are consistent with the fact that in Quebec and in Belgium there are common parenting values and intervention guidelines for families with children with special needs that could be responsible for some similarities in specific reactions to emotions, but that the support given to parents with an ASD child varies in these countries, which may affect other specific reactions (Abdeljalil \& Changkakoti, 2009; Potvin et al., 2018).

Mothers emotional profiles, educational level, culture and reactions to their ASD child s emotions

Concerning bidirectional links between emotional openness dimensions and specific reactions to emotions, some positive and significant correlations for the whole sample showed that the better mothers' cognitive conceptual representation of their emotions was, the more they displayed problem-focused reactions and encouraged their child to express their negative emotions and the less they minimized negative emotions toward their ASD child. The way in which Quebec and Belgian mothers represented their feelings and emotions was thus related to specific supportive reactions to negative emotions, as suggested by Hofstede (2001) and Mesquita \& Walker (2003), who mentioned the potential impact of beliefs about emotional events on parental practices with regard to ERSBs. When mothers were aware of internal bodily indicators of emotions, they tended to encourage their ASD child more in the expression of negative emotions. The more aware they were of external bodily indicators of emotions, the more they used punitive reactions to negative emotions and encouragement of expression of positive emotions with their ASD child. These findings could suggest that 
mothers who are sensitive to internal feelings in their body are more likely to incite their ASD child to display and share his or her negative emotions, fear, anger and sadness in order to "let them out" and potentially receive support from others. When mothers are more conscious of displaying their emotions, they may have a strong experience of other people's reactions or the impact of social gaze, and may therefore wish to support their ASD child to better control his or her negative emotions, which are often interpreted as less socially acceptable, and to express positive feelings, as these offer an opportunity to interact positively with others. These findings partially confirmed Hypothesis H2a concerning links between specific dimensions of the maternal openness profile and mothers' specific reactions to children's emotions. Moreover, the results of the hierarchical regressions showed that the variance in the four maternal reactions to negative emotions were better predicted by the model, including culture, education level and dimensions of emotional openness in mothers (particularly their cognitive-conceptual representations of emotions) as predictors, but the percentages of explained variances varied for each reaction. This model explained $21 \%$ of the variance in problem-focused reaction, $21 \%$ of the variance in encouragement of emotional expression, $14 \%$ of the variance in comforting, and $10 \%$ of the variance in minimizing responses to child's negative emotions. Concerning maternal reactions to children's positive emotions, $5 \%$ of the variance in socialization was explained by the model including culture and maternal educational level as predictors. These findings show that the contribution of socio-cultural and educational factors and some emotional dimensions of maternal openness profiles contribute partially to explain the variation in specific supportive reactions, but rarely the variation in unsupportive reactions. Hypothesis $\mathrm{H} 2 \mathrm{a}$ of partial bidirectional or predictive links between emotional openness profiles in Belgian and Quebec mothers and specific reactions to their ASD children's emotions was partially confirmed for the specific reactions mentioned above. Along similar lines, Mazzone \& Nader-Grosbois (2017c) reported that mothers' supportive reactions toward their ASD children's emotions were predicted by their level of education and their emotional openness profiles (in particular their emotional expressiveness, cognitive representation of emotions, communication of emotions, and normative restrictions of affectivity.

Mothers reactions to emotions and individual factors, ToM and emotion regulation of their ASD child

Among individual factors in children (age, severity of ASD, five personality factors), only the personality factor of conscientiousness was positively and significantly linked with a specific maternal reaction, the encouragement of expression of positive emotions by the child. No other significant correlation was obtained between maternal reactions and these child factors. The maternal reaction of distress to children's negative emotions was significantly predicted (12\% of the variance) by a model including culture, age, severity of ASD, and personality of the child. Mothers' encouragement of children's negative emotions was also 
predicted ( $8 \%$ of the variance) by the same model and more precisely by culture as a significant predictor. These findings emphasized that very particular child factors and culture partially explain the variance in only three specific supportive reactions to positive or negative emotions and an unsupportive reaction to negative emotions. Very little support was found for Hypothesis H3a. Mazzone \& Nader-Grosbois (2017c) showed that only some personality factors in ASD children contribute to explain variance in two specific maternal reactions to positive emotions: notably openness to experience explained $14 \%$ of the variance in socialization; and conscientiousness explained $40 \%$ of encouragement.

Concerning links between ToM abilities in ASD children and maternal reactions to emotions, significant positive links were obtained with unsupportive reactions, distress, and discomfort, and a negative link with the supportive reaction of comforting to negative emotions. The results of hierarchical regression analyses showed that ToM abilities combined with age and severity of ASD in children explained partially the variance in maternal distress, comforting and problem-focused reactions to negative emotions, and global ToM or specific cognitive or affective ToM were the best predictors. These findings indicate that specific bidirectional and predictive links are involved in the dynamic between the understanding of affective or cognitive mental states by ASD children, irrespective of their age and the degree of their autistic symptoms, and mothers' particular reactions to negative emotions. Hypothesis H4a was only partially confirmed concerning the way in which ToM abilities displayed by ASD children are linked with specific maternal reactions to their emotions. The mutual specific impact of affective and cognitive ToM abilities in ASD children and some parental reactions to emotions was also pointed to by Mazzone \& Nader-Grosbois (2017b, 2017c).

In addition, emotion regulation in ASD children was only positively related to punitive reactions by mothers to negative emotions. The hierarchical regression analyses highlighted that children's emotion regulation, combined with age and severity of ASD, partially explained the variance in maternal socialization of positive emotions, but emotion regulation was the most significant predictor. Hypothesis $\mathrm{H} 4 \mathrm{a}$ also received very little support from these results, which show how emotion regulation displayed by ASD children was linked with or contributes to the variance in these two specific maternal reactions to their emotions. Bougher-Muckian et al. (2016) reported another link between emotion regulation in ASD children and encouragement by their mothers to express their emotions during their interactions. However, Mazzone (2018: p. 276) reported no significant link between emotion regulation in ASD children and any maternal reaction, but a predictive link was found between emotion regulation and fathers' comforting reaction to negative emotions.

\section{Mother-child conversations about emotions}

Cultural differences appeared in the frequency of supportive mother-child conversations about emotions and in the use of a variety of emotion-related 
verbs with ASD children; in both cases, Belgian mothers' scores were lower than those of Quebec mothers. However, the variety of words for each basic emotion (joy, anger, sadness, fear) was similar in the two cultural groups. Hypothesis H1c was confirmed, in the sense that these two French-speaking groups share similar vocabulary to designate these four emotions, but depending on the culture, talking about emotions with ASD children may be more fostered in the support given to mothers in Quebec in intervention programs, which are more focused on emotional abilities and encouraged in the Quebec cultural community, in general (Abdeljalil \& Changkakoti, 2009; Nédélec-Trohel et al., 2015; Potvin et al., 2018) than in Belgium.

Mothers' emotional profiles, educational level, culture and mother-child conversations about emotions

In the whole sample, only some specific dimensions of emotional openness in mothers were significantly correlated with aspects of mother-child conversations. Maternal perception of internal bodily indicators of emotions was positively linked with the frequency of mother-child conversations about emotions and the use of a variety of sadness terms. Maternal perception of external bodily indicators of emotions was positively related with the use of a variety of sadness terms in conversations. Maternal normative restrictions of affectivity were linked positively to the frequency of mother-child conversations about emotions. Hierarchical regression analyses indicated that only $7 \%$ of the variance of the frequency of mother-child conversations about emotions was explained by a model including culture and the mother's educational level. Hypothesis H2b of variance in mother-child conversations about emotions depending on maternal factors (educational level and culture) and emotional openness profiles was only partially confirmed by these results.

Mother-child conversations about emotions and individual factors, ToM and emotion regulation in ASD children

No significant correlation was obtained between individual factors in children (age, severity of ASD, five factors of personality) and the frequency of mother-child conversations. The hierarchical regression analyses showed that the model including culture, age, severity of ASD factors (and more precisely with culture as a significant predictor) explained $12 \%$ of the variance in mother-child conversations. However, these results emphasized that personality factors in children did not impact these conversations. Hypothesis $\mathrm{H} 3 \mathrm{~b}$ of variance in these conversations about emotions depending on individual factors in ASD children was only partially supported by these findings. Mazzone \& NaderGrosbois (2017c) found that the total number of emotional terms used by mothers of ASD children in these conversations was explained by the children's personality factor of extraversion (but not other individual factors).

Concerning bidirectional links between mother-child conversations and ASD children's socio-emotional abilities, several positive significant correlations were obtained between the variety of emotion-related verbs or emotional terms used in mother-child conversations and ASD children's ToM abilities and emotion 
regulation. In other words, the more frequently mothers conversed with their ASD children about emotions, the more they reported that their children had a good understanding of their own mental states and those of others, and regulated their emotions well. Conversely, mothers who perceived their ASD child as having better socio-emotional abilities were more likely to discuss emotions with their child, using a variety of emotional terms. However, when ToMI scores and emotion regulation or dysregulation of children were included among predictive child variables, no significant result was obtained in regression analyses in terms of predicting the frequency of mother-child conversations about emotions. These findings showed that there are bidirectional links between affective and cognitive ToM abilities in ASD children and several variables of mother-child conversations: their frequency and the variety of terms used by mothers to talk about positive and negative emotions. However, ToM and emotion regulation did not appear as predictors of the frequency of these mother-child conversations. Hypothesis $\mathrm{H} 4 \mathrm{~b}$ was thus partially confirmed, specifically concerning bidirectional links between ToM and emotion regulation abilities in ASD children and the way mothers and children discuss emotions and emotional terms and verbs used by mothers. Mazzone (2018) also reported a link between cognitive ToM (beliefs, thinking) and the number of emotional terms employed by mothers. Other studies have also emphasized that emotion regulation in ASD children is linked positively with involvement in parent-child interactions and conversations about emotions or mental states (Costa et al., 2019; Laurent \& Gorman, 2018), and their frequency (Beaudoin et al., 2021). Similarly, the emotional and behavioral problems of ASD children are less severe when parents converse about emotions and when the quality of emotional climate is better (as described by (Baker et al., 2011; Griffith et al., 2015; Hickey et al., 2020; Smith et al., 2008)).

Links between mothers reactions to emotions and mother-ASD child conversations on emotions

Concerning the coherence of emotion-related behaviors in mothers of ASD children, positive significant links were obtained for the whole sample between most maternal supportive reactions to negative emotions (comforting, problem-focused reactions, encouragement of expression) or positive emotions (socialization) and the frequency of mother-child conversations about emotions. In other words, mothers who discuss emotions with their ASD children are more likely to comfort their children, to encourage them to express their emotions, and to react by focusing on problem-solving when their child feels negative emotions, and are also more likely to socialize their child's positive emotions. No unsupportive reaction was linked with the frequency of these emotion-related conversations. Hypothesis $\mathrm{H} 5$ was confirmed concerning bidirectional links between supportive maternal reactions to emotions felt by ASD children and the frequency of mother-child conversations about emotions. These findings emphasized a coherence and bidirectional links between these two kinds of emo- 
tion-related behaviors in Belgian and Quebec mothers' socialization practices with their ASD children, which may act as protective factors in their socioemotional development.

\section{Conclusion}

To conclude, this study has found that several factors should be considered as favorable to the use by mothers of specific supportive reactions and emotionrelated conversations. These factors vary depending on the type of reaction to negative or positive emotions and the indices considered in conversations. It seems important to take account of parents' educational level, cultural factors affecting their emotional openness profiles in order to adapt the support and intervention provided for parents and their ASD children so as to improve their mutual competences in this domain of socialization of emotions in a way that reflects their socio-cultural context. It also appears essential to take account of the severity of ASD and of ToM profiles related to affective and cognitive mental states, in order to give parents of ASD children better guidance about how to react to their children's emotions. The parents' attributions of negative and positive emotions in their ASD children may also have an impact on reactions and conversations about emotions, and on adaptive functioning and emotion regulation or dysregulation (as suggested by a study conducted by (Bougher-Muckian et al., 2019). The study also showed the relevance of examining bidirectional links between socio-emotional abilities in children and ERSBs in parents, integrating both individual and cultural factors, as suggested by (Keller, 2007; Kuczynski et al., 1997; Trommsdorff \& Kornadt, 2003).

The limitations of this study are as follows. The sample is small and concerns only two French-speaking countries limiting the significance of the results. As the children presented mild to moderately severe ASD, the results concerning mothers' ERSBs should be treated with caution, as this variable contributes to explaining variances in some reactions and the frequency of conversations about emotions. Emotional openness profiles, reactions and conversations on the part of the fathers of these ASD children were not included in either cultural sample. There were no direct performance measures of the children's socio-emotional abilities and no observation of parental ERSBs, because only other-reported measures were used. The children's levels of comprehensive and expressive language and pragmatic level of communication were not assessed by means of specific tests, despite the fact that these variables could have an impact on mother-child conversations about emotions. Aspects of the support given to parents while their children were at preschool and school were not evaluated systematically in order to assess the potential contribution of this variable to predicting their ERSBs toward their ASD children.

For future research, we recommend testing similar hypotheses on the socialization of emotions in a larger sample of parents of ASD children from several countries and cultures, in order to deepen and nuance the findings obtained in 
this study. We suggest that future studies investigate how various indices of conversations about emotions and mental states (cognitive and affective) and the use of emotional and mental terms, recorded in an observational design, are predicted by cultural, educational factors, parents' emotional profiles and type of parental support on one hand, and by individual factors and competences in ASD children on the other hand. Research is needed to validate an observation checklist for parent-child discussions of emotions and mental states, taking into account the content, the pragmatic function, and the type of strategies (questions, explanations, descriptions, link with life experience, etc.) used by each partner, in order to explore in detail the factors that support or impede good practice in these conversations. It could be interesting to test the differentiated effect of intervention programs targeting parents' socialization of emotions on their ERSBs in experimental studies (for example, (Havighurst et al., 2010) conducted studies of the effectiveness of the "Tuning into Kids" program). Moreover, longitudinal studies are needed to analyze reactions to emotions and parent-child discussions and their links with social cognition, emotion regulation and social behavior, in TD and atypically children in families of different cultures and socio-economic levels, measuring not only individual child factors, but also parent factors such as cognitive and emotional profiles, warmth, coparenting competences, and social support received, that could moderate links between ERSBs and socio-emotional abilities (as suggested by (Westrupp et al., 2020)). Finally, other social family factors need to be explored in the socialization of emotions and the support of socio-emotional abilities in ASD children; as suggested by Eymard et al. (2021), an examination of the role of siblings of ASD children in social emotion sharing, reactions and conversations about emotions and mental states could improve our understanding of ASD children's socioemotional profiles

\section{Acknowledgements}

We would like to thank the Chair Baron Frère in special education for their financial support. We also are really grateful to all the children and parents who took part in our studies.

\section{Conflicts of Interest}

The authors declare no conflicts of interest regarding the publication of this paper.

\section{References}

Abdeljalil, A., \& Changkakoti, N. (2009). Les relations entre parents et enseignants: Bilan des recherches récentes. Revue internationale de l'éducation familiale, 25, 103-130. https://doi.org/10.3917/rief.025.0103

Adrian, J. E., Clemente, R. A., Villanueva, L., \& Rieffe, C. (2005). Parent-Child Picture Book Reading, Mothers' Mental State Language and Children's Theory of Mind. Journal of Child Language, 32, 673-686. https://doi.org/10.1017/S0305000905006963

Astington, J. W. (1996). What Is Theoretical about the Child's Theory of Mind? A Vy- 
gotskian View of Its Development. In P. Carruthers, \& P. K. Smith (Eds.), Theories of Theories of Mind (pp. 184-199). Cambridge University Press. https://doi.org/10.1017/CBO9780511597985.013

Baeza-Velasco, C., Poirier, N., Nader-Grosbois, N., \& Cappe, É. (2019). Élever un enfant ayant un trouble du spectre de l'autisme: quel impact sur le couple ? In C. Derguy et É. Cappe (Eds.), Familles et trouble du spectre de l'autisme (pp. 238-245). Dunod.

Baker, J. K., Smith, L. E., Greenberg, J. S., Seltzer, M. M., \& Taylor, J. L. (2011). Change in Maternal Criticism and Behavior Problems in Adolescents and Adults with Autism across a 7-Year Period. Journal of Abnormal Psychology, 120, 465-475.

https://doi.org/10.1037/a0021900

Baron-Cohen, S., Leslie, A. M., \& Frith, U. (1985). Does the Autistic Child have a "Theory of Mind"? Cognition, 21, 37-46. https://doi.org/10.1016/0010-0277(85)90022-8

Beaudoin, M.-J., Poirier, N., \& Nader-Grosbois, N. (2021).The Relationships between Mother-Child Conversations about Emotion and the Socioemotional Development of Children with autism Spectrum disorder. Journal of Autism and Developmental Disorders. https://doi.org/10.1007/s10803-021-05267-3

Bornstein, M., \& Bradley, R. (2003). Socioeconomic Status, Parenting, and Child Development. Erlbaum.

Bougher-Muckian, H. R., Root, A. E., Coogle, C. G., \& Floyd, K. K. (2016). The Importance of Emotions: The Socialization of Emotion in Parents of Children with Autism Spectrum Disorder. Early Child Development and Care, 186, 1584-1593.

https://doi.org/10.1080/03004430.2015.1112799

Bougher-Muckian, H. R., Root, A. E., Floyd, K. K., Grygas Coogle, C., \& Hartman, S. (2019). The Association between Adaptive Functioning and Parents' Attributions for Children's Emotions. Early Child Development and Care, 189, 1538-1552.

https://doi.org/10.1080/03004430.2017.1396979

Brown, G. L., Craig, A. B., \& Halberstadt, A. G. (2015). Parent Gender Differences in Emotion Socialization Behaviors Vary by Ethnicity and Child Gender. Parenting: Science and Practice, 15, 135-157. https://doi.org/10.1080/15295192.2015.1053312

Brumariu, L. E., \& Kerns, K. A. (2015). Mother-Child Emotion Communication and Childhood Anxiety Symptoms. Cognition and Emotion, 29, 416-431. https://doi.org/10.1080/02699931.2014.917070

Burke, J., Pardini, D., \& Loeber, R. (2008). Reciprocal Relationships between Parenting Behavior and Disruptive Psychopathology from Childhood through Adolescence. Journal of Abnormal Child Psychology, 36, 679-692. https://doi.org/10.1007/s10802-008-9219-7

Cai, R. Y., Richdale, A. L., Uljarević, M., Dissanayake, C., \& Samson, A. C. (2018). Emotion Regulation in Autism Spectrum Disorder: Where We Are and Where We Need to Go. Autism Research, 11, 962-978. https://doi.org/10.1002/aur.1968

Camras, L., Kolmodin, K., \& Chen, Y. (2008). Mothers' Self-Reported Emotional Expression in Mainland Chinese, Chinese American and European American families. International Journal of Behavioral Development, 32, 459-463. https://doi.org/10.1177/0165025408093665

Cappe, E., Pedoux, A., Poirier, N., Downes, N., \& Nader-Grosbois, N. (2020). Adaptation and Quality of Life of Parents with a Child with Autism Spectrum Disorder: A Comparative Exploratory Study between France, French-Speaking Belgium and Quebec. Psychologie Française, 65, 141-155. https://doi.org/10.1016/j.psfr.2018.11.002

Cappe, É., Poirier, N., Boujut, É., Nader-Grosbois, N., Dionne, C., \& Boulard, A. (2017). Trouble du spectre de l'autisme et évaluation du stress perçu des parents et des 
professionnels: Étude des propriétés psychométriques d'une adaptation francophone de l'Appraisal of Life Event Scale (ALES-vf). L'Encéphale, 43, 321-325. https://doi.org/10.1016/j.encep.2016.08.001

Cole, P. M., \& Tan, P. Z. (2007). Emotion Socialization from a Cultural Perspective. In J. E. Grusec, \& P. D. Hastings (Eds.), Handbook of Socialization: Theory and Research (pp. 516-542). Guilford.

Cole, P. M., Tamang, B. L., \& Shrestha, S. (2006). Cultural Variations in the Socialization of Young Children's Anger and Shame. Child Development, 77, 1237-1251. https://doi.org/10.1111/j.1467-8624.2006.00931.x

Copapci, F., Friedlmeier, W., Benga, O., Strauss, C., Ptitica, I., \& Susa, G. (2017). Culutral Socialization of Toddlers in Emotionally Charged Situations. Social Development, 27, 262-278. https://doi.org/10.1111/sode.12272

Corbett, B. A., Constantine, L. J., Hendren, R., Rocke, D., \& Ozonoff, S. (2009). Examining Executive Functioning in Children with Autism Spectrum Disorder, Attention Deficit Hyperactivity Disorder and Typical Development. Psychiatry Research, 166, 210-222. https://doi.org/10.1016/j.psychres.2008.02.005

Costa, A. P., Steffgen, G., \& Vögele, C. (2019). The Role of Alexithymia in Parent-Child Interaction and in the Emotional Ability of Children with Autism Spectrum Disorder. Autism Research, 12, 458-468. https://doi.org/10.1002/aur.2061

Coutu, S., Dubeau, D., Provost, M. A., Royer, N., \& Lavigueur, S. (2002). Validation de la version française du questionnaire: Coping with Children's Negative Emotions ScaleCCNES. Revue canadienne des sciences du comportement, 34, 230-234. https://doi.org/10.1037/h0087175

Cui, L., Criss, M. M., Ratliff, E., Wu, Z., Houltberg, B. J., Silk, J. S., \& Morris, A. S. (2020). Longitudinal Links between Maternal and Peer Emotion Socialization and Adolescent girls' Socio-Emotional Adjustment. Developmental Psychology, 56, 595-607. https://doi.org/10.1037/dev0000861

Daffe, V., \& Nader-Grosbois, N. (2009). Réactions parentales face aux émotions de leur enfant: Adaptation intégrée de deux instruments. In N. Nader-Grosbois (Ed.), Résilience, régulation et qualité de vie: Concepts, évaluation et intervention (pp. 143-159). Presses Universitaires de Louvain.

Denham, S. A., Bassett, H. H., \& Wyatt, T. (2007). The Socialization of Emotional Competence. In J. E. Grusec, \& P. D. Hastings (Eds.), Handbook of Socialization: Theory and Research (pp. 614-637). The Guilford Press.

Denham, S. A., Zoller, D., \& Couchoud, E. A. (1994). Socialization of Preschoolers' Emotion Understanding. Developmental Psychology, 30, 928-936.

https://doi.org/10.1037/0012-1649.30.6.928

Dunsmore, J. C., \& Halberstadt, A. G. (1997). How Does Family Emotional Expressiveness Affect Children's Schemas? New Directions for Child Development, 1997, 45-66. https://doi.org/10.1002/cd.23219977704

Dunsmore, J. C., \& Halberstadt, A. G. (2009). The Dynamic Context of Children's Emotions: Family and Cultural System Influences. In J. A. Mancini, \& K. A. Roberto (Eds.), Pathways of Human Development: Explorations of Change (pp. 171-190). Lexington Books.

Eisenberg, N. (2020). Findings, Issues, and New Directions for Research on Emotion Socialization. Developmental Psychology, 56, 664-670. https://doi.org/10.1037/dev0000906

Eisenberg, N., \& Spinrad, T. L. (2004). Emotion-Related Regulation: Sharpening the Definition. Child Development, 75, 334-339. https://doi.org/10.1111/j.1467-8624.2004.00674.x 
Eisenberg, N., Cumberland, A., \& Spinrad, T. L. (1998). Parental Socialization of Emotion. Psychological Inquiry, 9, 241-273. https://doi.org/10.1207/s15327965pli0904_1

Eisenberg, N., Fabes, R. A., \& Murphy, B. C. (1996). Parents' Reactions to Children's Negative Emotions: Relations to Children's Social Competence and Comforting Behavior. Child Development, 67, 2227-2247. https://doi.org/10.2307/1131620

Eisenberg, N., Fabes, R. A., Shepard, S. A., Guthrie, I. K., Murphy, B. C., \& Reiser, M. (1999). Parental Reactions to Children's Negative Emotions: Longitudinal Relations to Quality of Children's Social Functioning. Child Development, 70, 513-534. https://doi.org/10.1111/1467-8624.00037

Eisenberg, N., Valiente, C., Morris, A. S., Fabes, R. A., Cumberland, A., Reiser, M. et al. (2003). Longitudinal Relations among Parental Emotional Expressivity, Children's Regulation, and Quality of socioemotional functioning. Developmental Psychology, 39, 3-19. https://doi.org/10.1037/0012-1649.39.1.3

Eymard, M., Poirier, N. \& Nader-Grosbois, N. (2021). L'effet de la présence et de l'absence de fratrie sur le niveau d'adaptation sociale des enfants présentant un trouble du spectre de l'autisme. Devenir, 33, 5-22. https://doi.org/10.3917/dev.211.0005

Fabes, R. A., Poulin, R. E., Eisenberg, N., \& Madden-Derdich, D. A. (2002). The Coping with Children's Negative Emotions Scale (CCNES): Psychometric Properties and Relations with Children's Emotional Competence. In R. A. Fabes (Ed.), Emotions and the Family (pp. 285-309). The Haworth Press, Inc.

Fivush, R., \& Wang, Q. (2005). Emotion Talk in Mother-Child Conversations of the Shared Past: The Effects of Culture, Gender, and Event Valence. Journal of Cognition and Development, 6, 489-506. https://doi.org/10.1207/s15327647jcd0604_3

Fivush, R., Brotman, M., Buckner, J., \& Goodman, S. (2000). Gender Differences in Parent-Child Emotion Narratives. Sex Roles, 42, 233-253.

https://doi.org/10.1023/A:1007091207068

Fivush, R., Marin, K. A., McWilliams, K., \& Bohanek, J. G. (2009). Family Reminiscing Style: Parent Gender and Emotional Focus in Relation to Child Well-Being. Journal of Cognition and Development, 10, 210-235. https://doi.org/10.1080/15248370903155866

Flavell, J. H. (1999). Cognitive Development: Children's Knowledge about the Mind. Annual Review of Psychology, 50, 21-45. https://doi.org/10.1146/annurev.psych.50.1.21

Friedlmeier, W., Corapci, F., \& Benga, O. (2015). Early Emotional Development in Cultural Perspective. In L. Jensen (Ed.), Oxford Handbook of Human Development and Culture: An Interdisciplinary Perspective (pp. 127-148). Oxford University Press.

Garner, P. W. (2006). Prediction of Prosocial and Emotional Competence from Maternal Behaviour in African American Preschoolers. Cultural Diversity and Ethnic Minority Psychology, 12, 179-198. https://doi.org/10.1037/1099-9809.12.2.179

Garner, P. W., \& Estep, K. M. (2001). Emotional Competence, Emotion Socialization, and Young Children's Peer-Related Social Competence. Early Education and Development, 12, 29-48. https://doi.org/10.1207/s15566935eed1201_3

Garner, P. W., Dunsmore, J. C., \& Southam-Gerrow, M. (2008). Mother-Child Conversations about Emotions: Linkages to Child Aggression and Prosocial Behavior. Social Development, 17, 259-277. https://doi.org/10.1111/j.1467-9507.2007.00424.x

Garner, P. W., Jones, D. C., Gaddy, G., \& Rennie, K. (1997). Low-Income Mothers' Conversations about Emotions and Their Children's Emotional Competence. Social Development, 6, 37-52. https://doi.org/10.1111/j.1467-9507.1997.tb00093.x

Garner, P. W., Robertson, S., \& Smith, G. (1997). Preschool Children's Emotional Expressions with Peers: The Roles of Gender and Emotion Socialization. Sex Roles, 36, 675-691. https://doi.org/10.1023/A:1025601104859 
Gomez, C. R., \& Baird, S. (2005). Identifying Early Indicators for Autism in Self-Regulation Difficulties. Focus on Autism and Other Developmental Disabilities, 20, 106-116. https://doi.org/10.1177/10883576050200020101

Griffith, G. M., Hastings, R. P., Petalas, M. A., \& Lloyd, T. J. (2015). Mothers’ Expressed Emotion towards Children with Autism Spectrum Disorder and Their Siblings. Journal of Intellectual Disability Research, 59, 580-587. https://doi.org/10.1111/jir.12178

Grusec, J. E. (2002). Parental Socialization and Children's Acquisition of Values. In M. H. Bornstein (Ed.), Handbook of Parenting (2nd ed., Vol. 5, pp. 143-167). Erlbaum.

Gulsrud, A. C., Jahromi, L. B., \& Kasari, C. (2010). The Co-Regulation of Emotions between Mothers and Their Children with Autism. Journal of Autism and Developmental Disorders, 40, 227-237. https://doi.org/10.1007/s10803-009-0861-x

Halberstadt, A. G., Denham, S. A., \& Dunsmore, J. (2001). Affective Social Competence. Social Development, 10, 79-119. https://doi.org/10.1111/1467-9507.00150

Halberstadt, A. G., Fox, N. A., \& Jones, N. A. (1993). Do Expressive Mothers Have Expressive Children? The Role of Socialization in Children's Affect Expression. Social Development, 2, 48-65. https://doi.org/10.1111/j.1467-9507.1993.tb00004.x

Havighurst, S. S., Wilson, K. R., Harley, A. E., Prior, M. R., \& Kehoe, C. (2010). Tuning into Kids: Improving Emotion Socialization Practices in Parents of Preschool Children-Findings from a Community Trial. Journal of Child Psychology and Psychiatry, 51, 1342-1350. https://doi.org/10.1111/j.1469-7610.2010.02303.x

Hickey, E. J., Nix, R., \& Hartley, S. L. (2020). Family Emotional Climate and Children with Autism Spectrum Disorder. Journal of Autism and Developmental Disorders, 49, 3244-3256. https://doi.org/10.1007/s10803-019-04037-6

Hofstede, G. (2001). Culture's Consequences: Comparing Values, Behaviors, Institutions and Organizations across Nations. Sage Publications.

Houssa, M., Mazzone, S., \& Nader-Grosbois, N. (2014). Validation d'une version francophone de l'Inventaire de la Théorie de l'Esprit. Revue Européenne de Psychologie Appliquée, 64, 169-179. https://doi.org/10.1016/j.erap.2014.02.002

Hutchins, T. L., \& Prelock, P. A. (2008). Considerations and Recommendations for Professionals Providing Services to Individuals with Autism Spectrum Disorder. Topic in Language Disorders, 28, 340-364. https://doi.org/10.1097/01.TLD.0000341128.01158.f2

Hutchins, T. L., Prelock, P. A., \& Bonazinga, L. (2012). Psychometric Evaluation of the Theory of Mind Inventory (ToMI): A Study of Typically Developing Children and Children with Autism Spectrum Disorder. Journal of Autism and Developmental Disorders, 42, 327-341. https://doi.org/10.1007/s10803-011-1244-7

Hutchins, T. L., Prelock, P. A., Morris, H., Benner, J., LaVigne, T., \& Hoza, B. (2016). Explicit vs. applied Theory of Mind Competence: A Comparison of Typically Developing Males, Males with ASD, and Males with ADHD. Research in Autism Spectrum Disorders, 21, 94-108. https://doi.org/10.1016/j.rasd.2015.10.004

Jacobs, E., Mazzone, S., Simon, P., \& Nader-Grosbois, N. (2019a). The Unexpected Impact of Parental Emotional Socialization on Theory of Mind and Emotion Regulation: The Case of Children with Intellectual Disabilities. Psychology, Special Issue on Developmental Psychology, 10, 1302-1332. https://doi.org/10.4236/psych.2019.109084

Jacobs, E., Mazzone, S., Simon, P., \& Nader-Grosbois, N. (2019b). The Unforeseen Influence of Parents' Socialization Behaviors on the Social Adjustment of Children with Intellectual Disabilities. Psychology, 10, 1275-1301.

https://doi.org/10.4236/psych.2019.109083

Jahromi, L. B., Bryce, C. I., \& Swanson, J. (2013). The Importance of Self-Regulation for the School and Peer Engagement of Children with High-Functioning Autism. Research in Autism Spectrum Disorders, 7, 235-246. https://doi.org/10.1016/j.rasd.2012.08.012 
Jahromi, L. B., Meek, S. E., \& Ober-Reynolds, S. (2012). Emotion Regulation in the Context of Frustration in Children with High Functioning Autism and Their Typical Peers. Journal of Child Psychology and Psychiatry, 53, 1250-1258. https://doi.org/10.1111/j.1469-7610.2012.02560.x

Jaramillo, J. M., Rendón, M. I., Muñoz, L., Weis, M., \& Trommsdorff, G. (2017). Children's Self-Regulation in Cultural Contexts: The Role of Parental Socialization Theories, Goals, and Practices. Frontiers in Psychology, 8, Article No. 923. https://doi.org/10.3389/fpsyg.2017.00923

Jenkins, J. M., Turrell, S. L., Kogushi, Y., Lollis, S., \& Ross, H. S. (2003). A Longitudinal Investigation of the Dynamics of Mental State Talk in Families. Child Development, 74, 905-920. https://doi.org/10.1111/1467-8624.00575

Jones, S., Eisenberg, N., Fabes, R. A., \& MacKinnon, D. P. (2002). Parents' Reactions to Elementary School Children's Negative Emotions: Relations to Social and Emotional Functioning at School. Merrill-Palmer Quarterly, 48, 133-159. https://doi.org/10.1353/mpq.2002.0007

Kay-Raining Bird, E., Cleave, P. L., Curia, J., \& Dunleavy, M. (2008). Parental Talk about Internal States to Their Child with Autism. Focus on Autism and Other Developmental Disabilities, 23, 166-175. https://doi.org/10.1177/1088357608319530

Keller, H. (2007). Cultures of Infancy. Erlbaum.

Kitayama, S., Mesquita, B., \& Karasawa, M. (2006). Cultural Affordances and Emotional Experience: Socially Engaging and Disengaging Emotions in Japan and the United States. Journal of Personality and Social Psychology, 91, 890-903. https://doi.org/10.1037/0022-3514.91.5.890

Konstantareas, M., \& Stewart, K. (2006). Affect Regulation and Temperament in Children with Autism Spectrum Disorder. Journal of Autism and Developmental Disorders, 36, 143-154. https://doi.org/10.1007/s10803-005-0051-4

Krause, E. D., Mendelson, T., \& Lynch, T. R. (2003). Childhood Emotional Invalidation and Adult Psychological Distress: The Mediating Role of Emotional Inhibition. Child Abuse, \& Neglect, 27, 199-213. https://doi.org/10.1016/S0145-2134(02)00536-7

Kuczynski, L., Marshall, S., \& Schell, K. (1997). Value Socialization in a Bidirectional Context. In J. E. Grusec, \& L. Kuczynski (Eds.), Parenting and Children's Internalization of Values: A Handbook of Contemporary Theory (pp. 23-50). Wiley.

LaBounty, J., Wellman, H. M., Olson, S., Lagattuta, K., \& Liu, D. (2008). Mothers' and Fathers' Use of Internal State Talk with Their Young Children. Social Development, 17, 757-775. https://doi.org/10.1111/j.1467-9507.2007.00450

Ladouceur, C., Reid, L., \& Jacques, A. (2002). Construction et validation du Questionnaire sur les réactions parentales aux émotions positives exprimées par l'enfant. Canadian Journal of Behavioural Science, 34, 8-18.

https://doi.org/10.1037/h0087150

Lagattuta, K. H., \& Wellman, H. M. (2002). Differences in Early Parent-Child Conversations about Negative versus Positive Emotions: Implications for the Development of Psychological Understanding. Developmental Psychology, 38, 564-580. https://doi.org/10.1037/0012-1649.38.4.564

Laible, D. (2004). Mother-Child Discourse in Two Contexts: Links with Child Temperament, Attachment Security, and Socioemotional Competence. Developmental Psychology, 40, 979-992. https://doi.org/10.1037/0012-1649.40.6.979

Laible, D. (2011). Does It Matter If Preschool Children and Mothers Discuss Positive vs. Negative Events during Reminiscing? Links with Mother-Reported Attachment, Family Emotional Climate, and Socioemotional Development. Social Development, 20, 394-411. 
https://doi.org/10.1111/j.1467-9507.2010.00584.x

Laible, D., \& Song, J. (2006). Constructing Emotional and Relational Understanding: The Role of Affect and Mother-Child Discourse. Merrill-Palmer Quarterly, 52, 44-69. https://doi.org/10.1353/mpq.2006.0006

Laurent, A. C., \& Gorman, K. (2018). Development of Emotion Self-Regulation among Young Children with Autism Spectrum Disorders: The Role of Parents. Journal of Autism and Developmental Disorders, 48, 1249-1260. https://doi.org/10.1007/s10803-017-3430-8

Loveland, K. A. (2005). Social-Emotional Impairment and Self-Regulation in Autism Spectrum Disorders. In J. Nadel, \& D. Muir (Eds.), Emotional Development: Recent Research Advances (pp. 365-382). Oxford University Press. https://doi.org/10.1093/acprof:oso/9780198528845.003.0014

Lozada, F. T., Halberstadt, A. G., Craig, A. B., Dennis, P. A., \& Dunsmore, J. C. (2016). Parents' Beliefs about Children's Emotions and Parents' Emotion-Related Conversations with Their Children. Journal of Child and Family Studies, 25, 1525-1538. https://doi.org/10.1007/s10826-015-0325-1

Manczak, E. M., Mngelsdorf, S. C., McAdams, D. P., Wong, M. S., Schoppe-Sullivan, S., \& Brown, G. L. (2016). “How Did That Make You Feel?” Influences of Gender and Parental Personality on Family Emotion Talk. Merrill-Palmer Quarterly, 62, 388-414. https://doi.org/10.13110/merrpalmquar1982.62.4.0388

Maskey, M., Warnell, F., Parr, J. R., Le Couteur, A., \& McConachie, H. (2013). Emotional and Behavioural Problems in Children with Autism Spectrum Disorder. Journal of Autism and Developmental Disorders, 43, 851-859. https://doi.org/10.1007/s10803-012-1622-9

Matthews, N. L., Goldberg, W. A., \& Lukowski, A. F. (2013). Theory of Mind in Children with Autism Spectrum Disorder: Do Siblings Matter? Autism Research, 6, 443-453. https://doi.org/10.1002/aur.1308

Mazefsky, C. A., Borue, X., Day, T. N., \& Minshew, N. J. (2014). Emotion Regulation Patterns in Adolescents with Highfunctioning Autism Spectrum Disorder: Comparison to Typically Developing Adolescents and Association with Psychiatric Symptoms. Autism Research, 7, 344-354. https://doi.org/10.1002/aur.1366

Mazzone, S. \& Nader-Grosbois, N. (2015). Comment les parents soutiennent-ils le développement émotionnel de leur enfant ? In I. Roskam, \& M. Mikolajczak (Eds.) Stress et défis de la parentalité, Thématiques contemporaines (pp. 153-168). De Boeck.

Mazzone, S. \& Nader-Grosbois, N. (2016). How Are Parental Reactions to Children's Emotions Related to Their Theory of Mind Abilities? Psychology, 7, 166-179. https://doi.org/10.4236/psych.2016.72019

Mazzone, S. \& Nader-Grosbois, N. (2017a). Variability and Predictors of Mothers and Fathers' Socialization Behaviors and Bidirectional Links with Their Preschoolers Socio-Emotional Competences. Journal of Behavioral and Brain Science, 7, 621-653. https://doi.org/10.4236/jbbs.2017.712043

Mazzone, S. \& Nader-Grosbois, N. (2017b). How Are Parental Reactions to Children's Emotions Linked with Theory of Mind Children with in Autism Spectrum Disorders? Research in Autism Spectrum Disorders, 40, 41-53. https://doi.org/10.1016/j.rasd.2017.05.003

Mazzone, S. \& Nader-Grosbois, N. (2017c). Emotion-Related Socialization Behaviours in Parents of Children with Autism Spectrum Disorders? Psychology, 8, 1134-1160. https://doi.org/10.4236/psych.2017.88074 
Mazzone, S. (2018). La socialisation parentale des émotions. comment les parents soutiennentils le développement socio-émotionnel denfants dâge préscolaire et présentant un trouble du spectre de Pautisme. Louvain-la-Neuve, Université Catholique de Louvain. Ph.D Dissertation (Directed by N. Nader-Grosbois).

http://hdl.handle.net/2078.1/199158

Mazzone, S., Roskam, I., \& Mikolajczak, M., \& Nader-Grosbois, N. (2017). The Questionnaire of Parent-Child Conversations about Emotions (QPCCE): Development and Validation of a Parent-Report Measure. Psychology, 8, 987-1007.

https://doi.org/10.4236/psych.2017.87065

McElwain, N. L., Halberstadt, A. G., \& Volling, B. L. (2007). Mother- and FatherReported Reactions to Children's Negative Emotions: Relations to Young Children's Emotional Understanding and Friendship Quality. Child Development, 78, 1407-1425. https://doi.org/10.1111/j.1467-8624.2007.01074.x

Mesquita, B., \& Walker, R. (2003). Cultural Differences in Emotions: A Context for Interpreting Emotional Experiences. Behaviour Research and Therapy, 41, 777-793. https://doi.org/10.1016/S0005-7967(02)00189-4

Meyer, S., Raikes, H. A., Virmani, E. A., Waters, S., \& Thompson, R. A. (2014). Parent Emotion Representations and the Socialization of Emotion Regulation in the Family. International Journal of Behavioral Development, 38, 164-173. https://doi.org/10.1177/0165025413519014

Mirabile, S. P., Oertwig, D., \& Halberstadt, A. G. (2016). Parent Emotion Socialization and Children's Socioemotional Adjustment: When Is Supportiveness No Longer Supportive? Social Development, 27, 466-481. https://doi.org/10.1111/sode.12226

Morelen, D., \& Suveg, C. (2012). A Real-Time Analysis of Parent-Child Emotion Discussions: The Interaction Is Reciprocal. Journal of Family Psychology, 26, 998-1003. https://doi.org/10.1037/a0030148

Morris, A. S., Silk, J. S., Steinberg, L., Myers, S. S., \& Robinson, L. R. (2007). The Role of the Family Context in the Development of Emotion Regulation. Social Development, 16, 361-388. https://doi.org/10.1111/j.1467-9507.2007.00389.x

Nader-Grosbois, N. (2011a). La théorie de l'esprit: Entre cognition, émotion et adaptation sociale. De Boeck. https://doi.org/10.3917/dbu.nader.2011.01

Nader-Grosbois, N. (2011b). Vers un modèle heuristique du fonctionnement et du développement social et émotionnel. In N. Nader-Grosbois (Ed.), la théorie de l'esprit: entre cognition, émotion et adaptation sociale (pp. 45-63). De Boeck.

https://doi.org/10.3917/dbu.nader.2011.01.0045

Nader-Grosbois, N., \& Cappe, E. (2015). Être parents d'un enfant présentant un trouble du spectre de l'autisme: Du stress... à une vie de meilleure qualité. In I. Roskam, \& M. Mikolajczak (Eds.), Stress et défis de la parentalité, Thématiques contemporaines (pp. 169-188). De Boeck.

Nader-Grosbois, N., \& Day, J. (2011). Emotional Cognition: Theory of Mind and Face Recognition. In J. Matson, \& P. Sturney (Eds.), International Handbook of Autism and Pervasive Developmental Disorders (pp. 127-157). Springer. https://doi.org/10.1007/978-1-4419-8065-6_9

Nader-Grosbois, N., \& Mazzone, S. (2014). Emotion Regulation, Personality and Social Adjustment in Children with Autism Spectrum Disorders. Psychology, 5, 1750-1767. https://doi.org/10.4236/psych.2014.515182

Nader-Grosbois, N., \& Mazzone, S. (2015). Validation de la version francophone de l'Inventaire de Régulation émotionnelle. Revue Européenne de Psychologie Appliquée, 65, 29-41. https://doi.org/10.1016/j.erap.2014.10.002 
Nader-Grosbois, N., \& Thirion-Marissiaux, A. F. (2011). Evaluer la compréhension des états mentaux «émotions» et "croyances». In N. Nader-Grosbois (Ed.), Théorie de l'esprit: Entre cognition, émotion et adaptation sociale chez des personnes typiques et atypiques (pp. 93-124). De Boeck. https://doi.org/10.3917/dbu.nader.2011.01.0093

Nader-Grosbois, N., Baurain, C., \& Mazzone, S. (2012). Emotion Regulation, Social Cognition and Social Adjustment: Specificities in Children with Autism Spectrum Disorder. In C. E. Richardson, \& R. A. Wood (Eds.), Autism Spectrum Disorder (pp. 1-39). Nova Science Publishers, Inc.

Nader-Grosbois, N., Jacobs, E., \& Morin, D. (2022). Mothers' Socialization of Emotions and Socio-Emotional Competences in Children with and without Intellectual Disabilities in Belgium and Quebec. Psychology.

Nédélec-Trohel, I., Numa-Bocage, L., \& Kalubi, J.-C. (2015). Conceptions, pratiques et formations inclusives dans l'espace francophone (France, Suisse, Belgique, Québec). La nouvelle revue de l'adaptation et de la scolarisation, No. 70-71, 19-23. https://doi.org/10.3917/nras.070.0019

Ontai, L. L., \& Thompson, R. A. (2002). Patterns of Attachment and Maternal Discourse Effects on Children's Emotion Understanding from 3 to 5 Years of Age. Social Development, 11, 433-450. https://doi.org/10.1111/1467-9507.00209

Ontai, L. L., \& Thompson, R. A. (2008). Attachment, Parent-Child Discourse and Theory of Mind Development. Social Development, 17, 47-60. https://doi.org/10.1111/j.1467-9507.2007.00414.x

Perry, N. B., Calkins, S. D., Nelson, J. A., Leerkes, E. M., \& Marcovitch, S. (2012). Mothers' Responses to Children's Negative Emotions and Child Emotion Regulation: The Moderating Role of Vagal Suppression. Developmental Psychobiology, 54, 503-513. https://doi.org/10.1002/dev.20608

Peterson, C. C., Wellman, H. M., \& Liu, D. (2005). Steps in Theory of Mind Development for Children with Deafness or Autism. Child Development, 76, 502-517. https://doi.org/10.1111/j.1467-8624.2005.00859.x

Potvin, M., Dhume, F., Verhoeven, M., \& Ogay, T. (2018). La formation des enseignants sur la diversité et les rapports ethniques: Regard comparatif France, Québec, Belgique et Suisse. Éducation et Francophonie, 46, 30-50. https://doi.org/10.7202/1055560ar

Reese, E., Bird, A., \& Tripp, G. (2007). Children's Self-Esteem and Moral Self: Links to Parent-Child Conversations Regarding Emotion. Social Development, 16, 460-478. https://doi.org/10.1111/j.1467-9507.2007.00393.x

Reicherts, M., \& Genoud, P. (2012). Les instruments DOE: Développement, modélisation et caractéristiques psychométriques. In M. Reicherts (Ed.), L'ouverture émotionnelle: Une nouvelle approche du vécu et du traitement émotionnels (pp. 43-56). Mardaga.

Rieffe, C., Oosterveld, P., Terwogt, M. M., Mootz, S., Van Leeuwen, E., \& Stockmann, L. (2011). Emotion Regulation and Internalizing Symptoms in Children with Autism Spectrum Disorders. Autism: The International Journal of Research and Practice, 15, 655-670. https://doi.org/10.1177/1362361310366571

Rogé, B. (1989). Adaptation Française de l'échelle d'évaluation de l'autisme infantile (C.A.R.S). Editions d'Applications psychotechniques.

Roskam, I., de Maere-Gaudissart, A., \& Vandenplas-Holper, C. (2000). Mise au point d'un instrument d'évaluation de la personnalité des enfants à partir du Modèle à Cinq Facteurs. L'orientation Scolaire Professionnelle, 29, 661-672. https://doi.org/10.4000/osp.5779

Ruffman, T., Slade, L., \& Crowe, E. (2002). The Relation between Children's and Mothers' 
Mental State Language and Theory of Mind Understanding. Child Development, 73, 734-751. https://doi.org/10.1111/1467-8624.00435

Samson, A. C., Phillips, J. M., Parker, K. J., Shah, S., Gross, J. J., \& Hardan, A. Y. (2014). Emotion Dysregulation and the Core Features of Autism Spectrum Disorder. Journal of Autism and Developmental Disorders, 44, 1766-1772. https://doi.org/10.1007/s10803-013-2022-5

Samson, A. C., Wells, W. M., Phillips, J. M., Hardan, A. Y., \& Gross, J. J. (2015). Emotion Regulation in Autism Spectrum Disorder: Evidence from Parent Interviews and Children's Daily Diaries. Journal of Child Psychology and Psychiatry, 56, 903-913. https://doi.org/10.1111/jcpp.12370

Schopler, E., Reichler, R. J., DeVellis, R. F., \& Daly, K. (1980). Toward Objective Classification of Childhood Autism: Childhood Autism Rating Scale (CARS). Journal of Autism and Developmental Disorders, 10, 91-103. https://doi.org/10.1007/BF02408436

Shewark, E. A., \& Blandon, A. Y. (2015). Mothers' and Fathers' Emotion Socialization and Children's Emotion Regulation: A Within-Family Model. Social Development, 24, 266-284. https://doi.org/10.1111/sode.12095

Shields, A., \& Cicchetti, D. (1997). Emotion Regulation among School Age Children: The Development and Validation of a New Criterion Q-Sort Scale. Developmental Psychology, 33, 906-916. https://doi.org/10.1037/0012-1649.33.6.906

Simon, P., \& Nader-Grosbois, N. (2021). Preschoolers' Empathy Profiles and Their Social Adjustment. Frontiers in Psychology, 12, Article No. 782500. https://doi.org/10.3389/fpsyg.2021.782500

Slaughter, V., Peterson, C. C., \& Mackintosh, E. (2007). Mind What Mother Says: Narrative Input and Theory of Mind in Typical Children and Those on the Autism Spectrum. Child Development, 78, 839-858. https://doi.org/10.1111/j.1467-8624.2007.01036.x

Smith, L. E., Greenberg, J. S., Seltzer, M. M., \& Hong, J. (2008). Symptoms and Behavior Problems of Adolescents and Adults with Autism: Effects of Mother-Child Relationship Quality, Warmth, and Praise. American Journal on Mental Retardation, 113, 387-402. https://doi.org/10.1352/2008.113:387-402

Southam-Gerow, M., \& Kendall, P. (2002). Emotion Regulation and Understanding: Implication for Child Psychopathology and Therapy. Clinical Psychology Review, 22, 189-222. https://doi.org/10.1016/S0272-7358(01)00087-3

Steele, S., Joseph, R. M., \& Tager-Flusberg, H. (2003). Brief Report: Developmental Change in Theory of Mind Abilities in Children with Autism. Journal of Autism and Developmental Disorders, 33, 461-467. https://doi.org/10.1023/A:1025075115100

Ting, V., \& Weiss, J. A. (2017). Emotion Regulation and Parent Co-Regulation in Children with Autism Spectrum Disorder. Journal of Autism and Developmental Disorder, 47, 680-689. https://doi.org/10.1007/s10803-016-3009-9

Trommsdorff, G., \& Kornadt, H. J. (2003). Parent-Child Relations in Cross-Cultural Perspective. In L. Kuczynski (Ed.) Handbook of Dynamics in Parent-Child Relations (pp. 271-306). Sage. https://doi.org/10.4135/9781452229645.n14

Vygotsky, L. (1978). Interaction between Learning and Development. Readings on the Development of Children, 23, 34-41.

Westrupp, E. M., Macdonald, J. A., Bennett, C., et al. (2020). The Child and Parent Emotion Study: Protocol for a Longitudinal Study of Parent Emotion Socialization and Child Socioemotional Development. BMJ Open, 10, Article ID: e038124. https://doi.org/10.1136/bmjopen-2020-038124 
Wilson, B. J., Berg, J. L., Zurawski, M. E., \& King, K. A. (2013). Autism and Externalizing Behaviors: Buffering Effects of Parental Emotion Coaching. Research in Autism Spectrum Disorders, 7, 767-776. https://doi.org/10.1016/j.rasd.2013.02.005

Wong, M. S., Diener, M. L., \& Isabella, R. A. (2008). Parents' Emotion Related Beliefs and Behaviors and Child Grade: Associations with Children's Perceptions of Peer Competence. Journal of Applied Developmental Psychology, 29, 175-186. https://doi.org/10.1016/j.appdev.2008.02.003

Wong, M. S., McElwain, N. L., \& Halberstadt, A. G. (2009). Parent, Family, and Child Characteristics: Associations with Mother- and Father-Reported Emotion Socialization Practices. Journal of Family Psychology, 23, 452-463. https://doi.org/10.1037/a0015552

Yeates, K. O., Bigler, E. D., Dennis, M., Gerhardt, C. A., Rubin, K. H., Stancin, T., \& Vannatta, K. (2007). Social Outcomes in Childhood Brain Disorder: A Heuristic Integration of Social Neuroscience and Developmental Psychology. Psychological Bulletin, 133, 535-556. https://doi.org/10.1037/0033-2909.133.3.535 


\section{Appendix}

Appendix A. Example of one item of the Parental reactions questionnaire describing a situation eliciting negative emotion.

If my child lost an object that is important to him/her (his/her blanket) and reacts by crying:

a. I'm angry with him/her for not paying attention and then crying about it.

$\square 1 \quad \square 2 \quad \square 3 \quad \square 4 \quad \square 5 \quad \square 6 \quad \square 7$

b. I tell my child that his or her reaction is exaggerated.
$\square 1$
$\square 3$
$\square 4$
5
$\square 6$
$\square 7$

c. I help my child to think about places he/she hasn't looked before.
$\square 1$
$\square 2$
$\square 3$
$\square 4$
5
$\square 6$
$\square 7$

d. I distract my child by talking about happy things.
$\square 1$

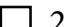
$\square$
$\square 6$

e. I tell him/her that it is normal to cry when you are sad.

$\square 1 \quad \square 2 \quad \square 3 \quad \square 4 \quad \square 5 \quad \square 6 \quad \square 7$

Appendix B. Example of one item of the Parental reactions questionnaire describing a situation eliciting positive emotion.

If we are at a wedding ceremony in the church and my child is laughing with his/her little cousin sitting behind him/her:

a. I smile at my child to indicate my understanding.
$\square 1$
$\square 2$
3
4
$5 \square 6$
$\square 7$

b. I tell my child to turn around and be quiet.

$\square 1 \quad \square 2 \quad \square 3 \quad \square 4 \quad \square 5 \quad \square 6 \quad \square 7$

c. I feel embarrassed by my child's behavior.
$\square 1$
$\square 2$
$\square 3$
$\square$
5
$\square 6$
7

d. I tell my child not to laugh during a wedding ceremony because it upsets people things.
$\square 1$
$\square 2$
$\square 3$
$\square$
$4 \quad \square 5$
$5 \square 6$
$\square$ 